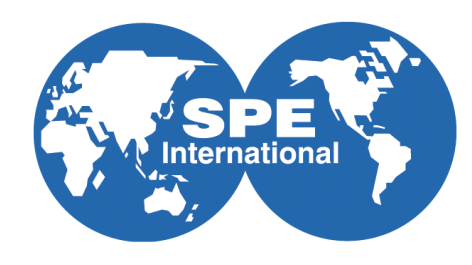

\title{
A Simple Physics-Based Model Predicts Oil Production from Thousands of Horizontal Wells in Shales
}

Tadeusz W. Patzek, Wardana Saputra, and Wissem Kirati

Ali I. Al-Naimi Petroleum Engineering Research Center (ANPERC), Physical Sciences and Engineering Division

King Abdullah University of Science and Technology (KAUST) Thuwal, Kingdom of Saudi Arabia 23955-6900

E-mail address: tadeusz.patzek@kaust.edu.sa

Copyright 2017, Society of Petroleum Engineers

This paper was prepared for presentation at the Annual Technical Conference and Exhibition held in San Antonio, Texas, U.S.A., 9-11 October 2017

This paper was selected for presentation by an SPE program committee following review of information contained in an abstract submitted by the author(s). Contents of the paper have not been reviewed by the Society of Petroleum Engineers and are subject to correction by the author(s). The material does not necessarily reflect any position of the Society of Petroleum Engineers, its officers, or members. Electronic reproduction, distribution, or storage of any part of this paper without the written consent of the Society of Petroleum Engineers is prohibited. Permission to reproduce in print is restricted to an abstract of not more than 300 words; illustrations may not be copied. The abstract must contain conspicuous acknowledgment of SPE copyright.

\section{Summary}

Over the last six years, crude oil production from shales ${ }^{1}$ and ultra-deep $\mathrm{GOM}^{2}$ in the United States has accounted for most of the net increase of global oil production. Therefore, it is important to have a good predictive model of oil production and ultimate recovery in shale wells. Here we introduce a simple model of producing oil and solution gas from the horizontal hydrofractured wells. This model is consistent with the basic physics and geometry of the extraction process. We then apply our model thousands of wells in the Eagle Ford shale.

Given well geometry, we obtain a one-dimensional nonlinear pressure diffusion equation that governs flow of mostly oil and solution gas. In principle, solutions of this equation depend on many parameters, but in practice and within a given oil shale, all but three can be fixed at typical values, leading to a nonlinear diffusion problem we linearize and solve exactly with a scaling "type" curve. After the initial 1-3 months of the generally unstable production, the scaled production rate declines as one over the square root of time early on and later it declines exponentially. The three governing parameters are the mean cumulative gas-oil ratio, GOR, the mass of saturated oil in place, $\mathcal{M}$, and the characteristic time of pressure interference between each pair of consecutive hydrofractures, $\tau$. This time depends on the effective formation permeability to oil, porosity, oil saturation, and the overall reservoir compressibility. GOR influences ultimate recovery, while the other two parameters determine where on the master curve production from a given well falls, depending on the $\mathcal{M}$, and how it stretches or shrinks, depending on the $\tau$. The distribution of $\tau$ also provides constraints on infill well locations. We implemented our automatic fitting procedure on a PC.

In February 2017, there were 13,057 physical oil wells in the Eagle Ford shale. However, there were only 4,734 unallocated well records because of the peculiar reporting requirements in Texas, explained in the paper. This means that up to 71 physical wells can be reported as one unallocated lease production record in the Eagle Ford. Since we are only interested in black oil horizontal wells, we have selected 2,611 wells with at least 6 months of oil production, GOR less than 2500 scf/stb and liquid gravity less than $40^{\circ}$ API. In practice, we match the production data for each well to a dimensionless

\footnotetext{
${ }^{1}$ Strictly speaking, the calcarious and silicious mudrock reservoirs in the Bakken, Eagle Ford, Permian, etc.

${ }^{2}$ Oil \& gas production from federal leases on the continental shelf in the Gulf of Mexico, Tainter and Patzek (2011).
} 
master curve with the recovery factor, $\mathrm{RF}=N_{p} / \mathcal{M}$, as the $y$-axis and the dimensionless time, $t / \tau$, as the $x$-axis. The match relies on adjusting the unknown parameters $\mathcal{M}$ and $\tau$. Here $N_{p}$ is cumulative mass production of oil and $t$ is elapsed time on production in months. 429 selected wells were still in the early time flow regime with $t / \tau<1$. In the remaining 2,182 wells, hydrofractures started pressure interfering in less than 46 months on production. Our scaling of production of the 2,611 black oil wells and back allocating production to the corresponding physical wells gives the total EUR close to 440 million bbl of oil.

Compared with reservoir simulation, the scaling curve method is more robust for thousands of wells and several orders of magnitude faster. Our method is especially useful for shale plays with limited access to reservoir data and it allows one to predict EURs of individual wells on a small laptop. Because we base our approach on the essential physics of oil recovery and on hydrofractured well geometry, the proposed method is highly predictive, while the popular hyperbolic decline curve analysis is not. To our knowledge, the proposed method is new.

KEYWORDS: Eagle Ford; black oil; EUR forecast; predictive robust model; fieldwide prediction

\section{Preliminaries}

The numbers of active oil and gas wells in the Eagle Ford are summarized in Table 1. Oil production in the Eagle Ford is an important part of shale oil production in the United States that has controlled global oil supply and prices over the last six years, see Fig. 1. Therefore, strategically, it is of utmost importance to have predictive models of shale oil production that go beyond the ad hoc hyperbolic decline curves and statistical studies. Here we attempt to satisfy parts of this strategic requirement.

To fix ideas, let's consider a typical black oil well in the Eagle Ford play, Texas. The typical horizontal well length is $1500 \mathrm{~m}(5000 \mathrm{ft})$, there are 12 stages with 4 clusters each, and we assume for the time being that there is one equivalent hydrofracture per stage with the tip-to-tip length, $2 L=400 \mathrm{~m}$; and height, $H$, equal to the formation thickness. The hydrofractures are spaced every $2 d=100 \mathrm{~m}$. For a cartoon of an idealized horizontal well, see Fig. 2.

After Gong (2013), we choose a well in the north-central part of the play, labeled as "PR3" in his Table 3.2 and others. PR3 is the largest oil-producing part of the Eagle Ford with the area of $6500 \mathrm{~km}^{2}$. A typical depth of the formation is $2400 \mathrm{~m}(7900 \mathrm{ft})$. The average formation thickness is $H=27 \mathrm{~m}(88 \mathrm{ft})$, the porosity is $\phi=8.6 \%$, and the connate water saturation is $S_{w c}=33 \%$. The estimated initial formation pressure is $p_{i}=36.7 \mathrm{MPa}$ (5600 psia), the oil gravity is $41^{0} \mathrm{API}$, and the typical dissolved gas oil ratio is $180 \mathrm{sm}^{3}$ of gas per $\mathrm{m}^{3}$ of stock tank oil ( $\left.\sim 1000 \mathrm{scf} / \mathrm{stb}\right)$. The downhole well pressure (fracture pressure) is $p_{f}=10.5 \mathrm{MPa}(1500 \mathrm{psi})$ and the wellhead tubing pressure is $P_{w h}=2 \mathrm{MPa}(300 \mathrm{psi})$. With the average temperature gradient of $3.6^{\circ} \mathrm{C} / 100 \mathrm{~m}\left(2^{0} \mathrm{~F} / 100 \mathrm{ft}\right)$ shown in Fig. 3, the reservoir temperature is $T=110^{0} \mathrm{C}$ $\left(230^{0} \mathrm{~F}\right)$. Average bubble point pressure in a PVT cell is $p_{b} \approx 30 \mathrm{MPa}$ (4300 psi). Average permeability of the calcite-rich matrix is $k \approx 0.1 \mu$ darcy. All qualifying black oil wells identified in the Eagle Ford are shown in Fig. 4. The cumulative GOR at the end of production history of each well is a circle plotted in Fig. 5. These GORs are divided into three classes, $\mathrm{GOR} \in[0,300],(300,900],(900,2500]$, identified in blue, green, and yellow. If the median cumulative production of stock tank oil in the first class is 1, then the remaining medians are 2.09 and 3.97; the produced mostly dissolved gas contributes significant mass. The corresponding cumulative mass produced by each well is shown in Fig. 6.

Table 1: Statistics of Eagle Ford oil wells accessed by DrillingInfo in Feb. 2017

\begin{tabular}{lll}
\hline Number & Unallocated & Allocated \\
\hline Oil wells & 4,734 & 13,057 \\
\hline Gas wells & 6,108 & 6,108 \\
\hline Total wells & 11,004 & 19,356 \\
\hline
\end{tabular}


The total compressibility of the pore space filled with oil, water and gas is the sum of the saturation weighted isothermal fluid compressibilities, $c_{o}, c_{w}$ and $c_{g}$, and the pore space compressibility, $c_{\phi}$ :

$$
c_{\text {fluid }}=\left(\frac{1}{\rho_{\text {fluid }}} \frac{\partial \rho_{\text {fluid }}}{\partial p}\right)_{T}, \quad \text { fluid }=o, w, g \quad c_{\phi}=\left(\frac{1}{\phi} \frac{\partial \phi}{\partial p}\right)_{T, p_{c}}
$$

where the pore space compressibility is measured under constant confining pressure, $p_{c}=\frac{1}{3}\left(S_{1}+S_{2}+S_{3}\right)$, equal to the trace of the total earth stress tensor, S, see Fig. A2. In particular, see Patzek et al. (2014),

$$
c_{g} \approx \frac{1}{p}
$$

If only oil flows when reservoir pressure decreases by $\delta p$, the total production at downhole conditions is equal to the expansions of all fluids plus shrinkage of the pore space:

$$
\begin{aligned}
\delta V_{t} & =\delta V_{o} \delta V_{w}+\delta V_{g}+\delta V_{\phi} \\
& =c_{o} V_{o} \delta p+c_{w} V_{w} \delta p+c_{g} V_{g} \delta p+c_{\phi} V_{\phi} \delta p=\phi V \underbrace{\left(S_{o} c_{o}+S_{w} c_{w}+S_{g} c_{g}+c_{\phi}\right)}_{=c_{t}} \delta p \\
\mathrm{RF} & =\frac{\delta V_{t}}{\phi V S_{o i}}=\frac{c_{t}}{S_{o i}} \delta p, \quad \delta p \equiv p_{i}-\langle p\rangle
\end{aligned}
$$

where $S_{o i}$ is the initial oil saturation and RF is the recovery factor, calculated as cumulative oil production divided by the volume of oil initially in the pore space. To further fix ideas, a typical compressibility of light oil above the bubble point is $15 \times 10^{-6} \mathrm{psi}^{-1}$, water compressibility is $3 \times 10^{-6} \mathrm{psi}^{-1}$, and that of shale is $1 \times 10^{-6} \mathrm{psi}^{-1}$.

A plausible argument can be made that gas that evolves in the pore space after reservoir pressure falls below bubble point, remains trapped until its saturation builds above a high value, say, $S_{g c}=15-20 \%$, Honarpour et al. (2004). Because of interfacial tension and small radii, the nanometer scale gas bubbles are at a significantly higher pressure than oil. Therefore, reservoir pressure needs to drop below bubble point by $\sim 700$ psi to form these bubbles and sustain them, see Honarpour et al. (2004). Since ultimate oil recovery in a shale is of the order of 10 saturation percent, flowing gas develops only in the near-fracture regions where average reservoir pressure falls down to just above $1500 \mathrm{psi}$, and the saturation change of oil is larger than $15-20 \%$. This means that for a long time and in most of the pore space, gas remains dissolved in oil in the regions of the reservoir above the adjusted bubble point pressure, $P_{b}^{\prime}$. Below $P_{b}^{\prime}$, typical compressibility of trapped gas bubbles is shown in Fig. 7.

Once bubbles of trapped gas develop, their compressibility dominates the system compressibility and enhances oil recovery. At $\left\langle S_{g}\right\rangle \approx 0.02$, gas compressibility is as large as all other compressibilities combined: $S_{g} c_{g} \approx S_{o} c_{o}+S_{w} c_{w}+c_{\phi}$, see Fig. 7.

Below bubble point, let's assume that

$$
\begin{aligned}
S_{g} & =a+b p, p_{f} \leq p<p_{b}^{\prime}, p_{b}^{\prime}=p_{b}-\Delta p_{b}(\bar{r}) \\
b & =-\frac{S_{g, \max }}{p_{b}-p_{f}}, \quad a=-b p_{b}^{\prime} \\
\Delta V_{g} & =\int_{p_{b}}^{p} c_{g} S_{g} d p=\int_{p_{b}^{\prime}}^{p}\left(\frac{a}{p}+b\right) d p=a \ln \left(p / p_{b}^{\prime}\right)+b\left(p-p_{b}^{\prime}\right)
\end{aligned}
$$

where $p_{b}$ is the unconfined oil saturation pressure or bubble point pressure; $\Delta p_{b}$, a function of the mean pore radius, $\bar{r}$, is the lowering of bubble point in nanopores; and $\Delta V_{g}$ is an increase of gas volume due to increasing gas saturation and gas compressibility as average reservoir pressure falls from $\langle p\rangle=p_{b}^{\prime}$ to $\langle p\rangle \geq p_{f}$. Fig. 8 shows the results for $S_{g, \max }=0.15,0.10$, and 0.04. $P_{x}$ is defined as a number such that there is an $x \%$ likelihood that true RF exceeds $P_{x} . P_{50}$ is the median of the 
distribution with equal likelihoods, while $P_{10}$ denotes a $10 \%$ probability that true RF will be larger than $P_{10}$. The horizontal lines in Fig. 8 are the $P_{50}$ and $P_{10}$ recovery factors in a set of numerical simulations by Gong (2013) for a typical horizontal well in area P3 of the Eagle Ford. With all simulation parameters at their expected values listed above, Fig. 8 implies that there is a $10 \%$ probability of exceeding $\left\langle S_{g}\right\rangle=0.04$ even if reservoir pressure is uniformly depleted by 4,100 psi to $p_{f}=1500$ psia. Similarly, $\left\langle S_{g}\right\rangle<10 \%$ if the average reservoir pressure is $\langle p\rangle \geq 2000$ psia and $\left\langle S_{g}\right\rangle\langle 15 \%$ if $\langle p\rangle \geq 1800$ psia at well abandonment. We are not implying that near the hydrofractures gas saturation cannot build up to values above $S_{g c}$. It does, and gas in the highly fractured reservoir volume that surrounds each hydrofracture will flow producing a higher GOR at wellhead than the initial GOR. The GOR's in the identified black oil wells that correspond to their latest production times are shown in Fig. 5.

In summary, we assume that production of black oil can be modeled with a mildly nonlinear pressure diffusion equation as long as reservoir regions in which gas flows are limited in space and time.

\section{One-dimensional transient flow of black oil above or just below the bubble pressure}

Given the simplified picture of oil flow to a hydrofractured horizontal well depicted in Fig. 2, and the preliminary volumetric analysis above, a one dimensional pressure diffusion equation should be sufficient to model the oil and solution gas flow. After replacing the reference state, "0", introduced in Appendix A with the initial state of the reservoir, " $i$ ", the 1D version of Eqs. (A14) and (A15) is

$$
\begin{gathered}
\frac{\partial p}{\partial t}=\alpha(p) \frac{\partial^{2} p}{\partial x^{2}} \\
\alpha(p)=\left(\frac{k}{\phi c_{t} \mu_{o}}\right)\left(\frac{\rho_{o}}{\rho_{\text {fluid }, i}}\right)
\end{gathered}
$$

Just below the bubble point, we modify the total system compressibility as follows:

$$
\begin{aligned}
c_{t} & =S_{o i} c_{o}+S_{w c} c_{w}+S_{g} c_{g}+c_{\phi}=\underbrace{c_{\text {other }}}_{=\text {constant }}+S_{g} c_{g} \\
S_{g} c_{g} & \approx \frac{a}{p}+b \text { for } p<p_{b}^{\prime} \\
S_{g} & =0 \text { for } p \geq p_{b}^{\prime},
\end{aligned}
$$

see Eq. (4) and Figs. 7 and 8. With this extension, the pressure diffusivity coefficient, $\alpha$, is constant above bubble point and a nonlinear function of pressure below, see Fig. 9.

Production of oil and mostly solution gas from a horizontal well can be described as follows: Find the distribution of oil pressure in the region between each pair of vertical planar hydrofractures located at $\pm d$, with the uniform initial pressure, $p(x, t=0)=p_{i},-d<x<d$, and with both hydrofractures held at a constant pressure $p(x= \pm d, t>0)=p_{f}$. The thermodynamic pressure, or reservoir pressure, is equal to the oil pressure because gas is either in solution or forms mostly disconnected bubbles. The pressure diffusion Eq. (5) can be recast into a dimensionless using the following variables:

$$
\begin{aligned}
\tilde{p} & =\frac{p_{i}-p}{p_{i}} \\
\tilde{t} & =\frac{\alpha_{i}}{d^{2}} t \\
\tilde{x} & =\frac{x}{d},
\end{aligned}
$$

where $\alpha_{i}=\alpha\left(p_{i} \geq p_{b}, T\right)=$ const. Then Eq. (5) becomes

$$
\frac{\partial \tilde{p}}{\partial \tilde{t}}=\frac{\alpha}{\alpha_{i}} \frac{\partial^{2} \tilde{p}}{\partial \tilde{x}^{2}}
$$


subject to the following initial and boundary conditions:

$$
\begin{aligned}
& \tilde{p}(\tilde{x}, \tilde{t}=0)=0 \\
& \tilde{p}(\tilde{x}= \pm 1, \tilde{t}>0)=\frac{p_{i}-p_{f}}{p_{i}}=\tilde{p}_{f}
\end{aligned}
$$

From Eqs. (8) it follows that the dimensional gradient of pressure is

$$
\frac{\partial p}{\partial x}=-\frac{p_{i}}{d} \frac{\partial \tilde{p}}{\partial \tilde{x}}
$$

For a horizontal well segment between each two consecutive hydrofractures, the volumetric rate of oil production at the well downhole conditions $\left(p_{f}, T\right)$ is:

$$
q(\tilde{t} ; y)=-\left.2 \frac{k A_{f}}{\mu}\left(\frac{\partial p}{\partial x}\right)\right|_{x=-d}=-\left.2 \frac{k A_{f}}{\mu}\left(-\frac{p_{i}}{d}\right)\left(\frac{\partial \tilde{p}}{\partial \tilde{x}}\right)\right|_{\tilde{x}=-1}
$$

where $A_{f}=2 L H$ is the one-sided area of hydrofracture, and $y=\left[p_{f}, p_{i}, T, k, \mu, A_{f}\right]$ is the vector of process parameters.

Let's introduce now the initial mass of oil in place and the mass flow rate of oil at the downhole conditions

$$
\begin{aligned}
\mathcal{M} & =\rho_{o i} V=\rho_{o i} A_{f}(2 d) \phi S_{o i} \\
\dot{\mathbf{m}} & =\rho_{f} q .
\end{aligned}
$$

where $\rho_{f}$ is the fluid density at the pressure $p_{f}$ in the hydrofractures. Then

$$
\begin{aligned}
& \dot{\mathbf{m}}=-\left.\frac{\mathcal{M}}{\tau} \underbrace{\frac{\left(c_{t} p_{i}\right)}{S_{o i}}}_{\approx 0.1} \underbrace{\left(\frac{\rho_{\text {fluid }, i} \rho_{f}}{\rho_{o i}^{2}}\right)}_{\approx 1}\left(\frac{\partial \tilde{p}}{\partial \tilde{x}}\right)\right|_{\tilde{x}=-1} \\
& \dot{\mathbf{m}} \approx-\left.0.1 \frac{\mathcal{M}}{\tau}\left(\frac{\partial \tilde{p}}{\partial \tilde{x}}\right)\right|_{\tilde{x}=-1} \text { for average PR3 properties }
\end{aligned}
$$

Above and just below oil bubble pressure, the initial and boundary value problem given by Eqs. (9) and (10) can be solved immediately using the method of separation of variables, see, e.g., Carslaw and Jaeger (1959), p.100. The result is:

$$
\frac{\tilde{p}}{\tilde{p}_{f}}=1-\frac{4}{\pi} \sum_{n=0}^{\infty} \frac{(-1)^{n}}{2 n+1} \mathrm{e}^{\left(-(2 n+1)^{2} \pi^{2} \tilde{t} / 4\right)} \cos \left(\frac{(2 n+1) \pi \tilde{x}}{2}\right)
$$

Because of the exponential factor in each term of the series in Eq. (15), this series converges uniformly for all $x \in(-d, d)$ and all $t>0$. Therefore, to differentiate or integrate the left-hand side, each term on the right hand side can be differentiated or integrated separately.

The dimensionless pressure gradient at the hydrofracture at $\tilde{x}=-1$ is

$$
\left.\frac{\partial \tilde{p}}{\partial \tilde{x}}\right|_{\tilde{x}=-1}=-2 \tilde{p}_{f} \sum_{n=0}^{\infty}(-1)^{n} \mathrm{e}^{\left(-(2 n+1)^{2} \pi^{2} \tilde{t} / 4\right)} \sin \left(\frac{(2 n+1) \pi}{2}\right)
$$

Notice that for all $n$

$$
(-1)^{n} \sin \left(\frac{(2 n+1) \pi}{2}\right)=1
$$

and Eq. (16) reduces to

$$
\left.\frac{\partial \tilde{p}}{\partial \tilde{x}}\right|_{\tilde{x}=-1}=-2 \tilde{p}_{f} \sum_{n=0}^{\infty} \mathrm{e}^{\left(-(2 n+1)^{2} \pi^{2} \tilde{t} / 4\right)}
$$




$$
\begin{aligned}
\dot{\mathbf{m}} & =2 \frac{\mathcal{M}}{\tau} \frac{c_{t} p_{i}}{S_{o i}} \tilde{p}_{f} \sum_{n=0}^{\infty} \mathrm{e}^{\left(-(2 n+1)^{2} \pi^{2} \tilde{t} / 4\right)} \\
& =2 \frac{\mathcal{M}}{\tau} \frac{c_{t}}{S_{o i}}\left(p_{i}-p_{f}\right) \sum_{n=0}^{\infty} \mathrm{e}^{\left(-(2 n+1)^{2} \pi^{2} \tilde{t} / 4\right)}
\end{aligned}
$$

The oil recovery factor is

$$
\mathrm{RF}=\frac{\tau}{\mathcal{M}} \int_{0}^{t / \tau} \dot{\mathbf{m}}\left(t^{\prime} / \tau\right) d\left(t^{\prime} / \tau\right)=\frac{c_{t}}{S_{o i}}\left(p_{i}-p_{f}\right) \sum_{n=0}^{\infty} \int_{0}^{\tilde{t}} \mathrm{e}^{\left(-(2 n+1)^{2} \pi^{2} \tilde{t}^{\prime} / 4\right)} d \tilde{t}^{\prime}
$$

The term-by-term integration of the series in Eq. (20) yields:

$$
\underbrace{\frac{4}{\pi^{2}} \sum_{n=0}^{\infty} \frac{1}{(2 n+1)^{2}}}_{1 / 2}-\frac{4}{\pi^{2}} \sum_{n=0}^{\infty} \frac{1}{(2 n+1)^{2}} \mathrm{e}^{\left(-(2 n+1)^{2} \pi^{2} \tilde{t} / 4\right)}
$$

After setting $\rho_{f} / \rho \approx 1$, the oil recovery factor becomes simply

$$
\mathrm{RF}=\frac{c_{t}}{S_{o i}}\left(p_{i}-p_{f}\right)\left(1-\frac{8}{\pi^{2}} \sum_{n=0}^{\infty} \frac{1}{(2 n+1)^{2}} \mathrm{e}^{\left(-(2 n+1)^{2} \pi^{2} \tilde{t} / 4\right)}\right)
$$

This is a satisfying result: If we wait long enough, and average reservoir pressure is still not too far from bubble point, the recovery factor will be equal to the oil recovered due to pore fluid expansion and pore space shrinkage under the overall pressure difference of $p_{i}-p_{f}$, see also Eq. (3). If the reservoir parameters and hydrofracture spacing remain unchanged during oil production, this recovery factor is universal.

At stock tank conditions, the mass of saturated oil produced at downhole conditions separates into stock tank (dead) oil and solution gas:

$$
\begin{aligned}
\dot{\mathbf{m}} & =\rho_{\mathrm{ST}} q_{\mathrm{ST}}+\rho_{g, \mathrm{ST}} R_{s} q_{\mathrm{ST}} \\
q_{\mathrm{ST}} & =\frac{\dot{\mathbf{m}}}{\rho_{\mathrm{ST}}+R_{s} \rho_{g, \mathrm{ST}}} \\
\rho_{\mathrm{ST}} & =1000 \frac{141.5}{131.5+A P I^{0}} \frac{\mathrm{kg} \text { oil }}{\mathrm{sm}^{3}} \\
\rho_{g, \mathrm{ST}} & =0.84 \frac{\mathrm{kg} \mathrm{gas}}{\mathrm{sm}^{3}}
\end{aligned}
$$

where $p_{\mathrm{ST}}=1 \mathrm{~atm}, T_{\mathrm{ST}}=288.7 \mathrm{~K}\left(60^{\circ} \mathrm{F}\right), R_{s}$ is the solution gas/oil ratio, and the gas density is that of natural gas. If a horizontal well has N' pairs of fractures, and the first and the last hydrofracture have unshared exterior sides, the production for the well will be $N^{\prime}+1=N$ times higher. Here $N$ is the total number of parallel, vertical hydrofractures in a horizontal well.

The cumulative oil production at stock tank conditions is

$$
Q_{S T}=N \int_{0}^{t} q_{S T}\left(t^{\prime}\right) d t^{\prime} \approx \sum_{i=1}^{n} q_{\text {field }, S T}\left(t_{i}\right) \Delta t_{i}=\tau \sum_{i=1}^{n} q_{\text {field }, S T}\left(t_{i} / \tau\right) \frac{\Delta t_{i}}{\tau}
$$

where $t$ is the elapsed time on production equal to $n$ months, $t_{i}$ is the $i^{\text {th }}$ month on production, and $q_{\text {field,ST }}\left(t_{i}\right)$ is the volume of oil produced in month $i$ by a horizontal well. "Time on production" is defined as the cumulative number of months with nonzero produced oil volumes. 


$$
\operatorname{RF}(t)=\operatorname{RF}(\tau \tilde{t})=\frac{\int_{0}^{t} \dot{\mathbf{m}}\left(t^{\prime}\right) d t^{\prime}}{\mathcal{M}} \approx \frac{\left(\rho_{\mathrm{ST}}+R_{s} \rho_{g, \mathrm{ST}}\right) \sum_{i=1}^{n} q_{\text {field }, S T}\left(t_{i}\right) \Delta t_{i}}{N \mathcal{M}}
$$

\section{Finding $\mathcal{M}$ and $\tau$ as a Nonlinear Least Squares Optimization Problem}

For each suitable well, we subtract Eq. (22) from (25) and take the square of the difference. The result is the following optimization problem: For each qualifying well with $t_{N_{\text {well }}} / \tau \geq 0.6$, see Patzek et al. $(2013,2014)$, find:

$$
\begin{aligned}
& \min _{\mathcal{M}>0, \tau>0} \mathcal{F}(\mathcal{M}, \tau, \ldots)= \\
& \sum_{j=1}^{N_{\text {well }}}\left[\rho_{\mathrm{ST}}+R_{s} \rho_{g, \mathrm{ST}} q_{f i e l d, S T}\left(t_{j}\right) \Delta t_{j}-\frac{c_{t}(N \mathcal{M})}{S_{o i}}\left(p_{i}-p_{f}\right)\left(1-\frac{8}{\pi^{2}} \sum_{n=0}^{\infty} \frac{1}{(2 n+1)^{2}} \mathrm{e}^{\left[-(2 n+1)^{2} \pi^{2} t_{j} /(4 \tau)\right]}\right)\right]^{2}
\end{aligned}
$$

where $N_{\text {well }}$ is the number of time intervals, here months, a given well was on production. A "qualifying well" is one with at least 6 months on production, and with stable production; we reject wells, whose cumulative oil production plots as a zigzag vs. time on production or plots as an upward pointing parabola vs. the square root of time on production. If the maximum time on production divided by an estimated pressure interference time $\tau$, is larger than one, a qualifying well is in infinite reservoir flow and its cumulative oil production plots as straight line vs the square root of time on production.

Calculating EUR. From the simulations, we obtained the value of $\tau$ (months) and $\mathcal{M}$ (ktons) for each allocated lease. Since we have adjusted three Recovery Factor (RF) values for the three different GOR tiers, we can directly calculate the predicted Estimated Ultimate Recovery (EUR) for the particular allocated lease as follows:

$$
\mathrm{EUR}_{\mathrm{avg}}=\mathrm{RF} \times \mathscr{M}(\text { ktons })
$$

Since we have assumed that we have allocated the lease production evenly up to the maximum number of wells, $n$, we further assume that the EUR for the lease is $n$ times of its average EUR avg $_{\text {: }}$

$$
\mathrm{EUR}_{\text {lease }}=n \times \mathrm{EUR}_{\mathrm{avg}}(\mathrm{ktons})
$$

To compare with the EIA's results, we may convert back the mass produced in ktons to its corresponding volume in bbls through the following conversion:

$$
\begin{aligned}
& \text { produced volume }(\text { boe })=\text { mass produced }(\text { ktons }) \times 10^{6} / 5.615 \frac{\mathrm{cuft}}{\mathrm{bbl}} /(0.3048)^{3} \frac{\mathrm{m}^{3}}{\mathrm{cuft}} \\
& \qquad /\left(\rho_{o}+\rho_{g} \times \frac{\mathrm{GOR}}{5.615}\right) \frac{\mathrm{kg}}{\mathrm{m}^{3}}
\end{aligned}
$$

\section{Results and Discussion}

The convolved production records in the Eagle Ford were untangled using an algorithm presented in Appendix B, leaving many fewer wells than the number of physical wells. In a forthcoming paper we will propose a few relatively inexpensive ways of remedying this serious deficiency of production reporting that in the long run will hurt operators, who may not know how each well in a lease gathering system performs with time. With infill drilling and subtler ways of operating individual wells, the current gap in reporting production data accurately must be filled.

The key results for the allocated oil wells are presented in Figs. 10 and 11. From both figures it follows that higher GOR helps to produce more oil by increasing the system compressibility somewhat. By "pressure interference," here we mean 
only the interference among pairs of the consecutive hydrofractures. This is the intra-well pressure interference. Here, we do not address the inter-well pressure interference, but it may show up as intra-well pressure interference of pad-drilled wells.

There are 428 wells that have not pressure-interfered after up to 44 months on production, and their cumulative production plots as straight lines vs. the square root of time on production. The remaining 2,182 wells have pressure-interfered and their cumulative production bends down when plotted vs. the square root of time, because of the exponential decline rate of production that becomes detectable at $t / \tau>0.6$.

The frequency distributions of interference times, $\tau$, are shown in Fig. 12 for the three classes of GOR values. Note that all three distributions have quite pronounced peaks around five years (60 months). It appears, therefore, that the most likely ratios pressure diffusivities to the square of interfracture distance are about the same regardless of well location and design. These ratios should be used when planning for infill wells.

Note that on average our physics-based modeling predictions are in agreement with a statistical study of the Eagle Ford wells by EIA, but there are significant differences, see Table 2:

- We select only wells that produce oil with API gravity less than 40 deg and cumulative GOR less than $2500 \mathrm{scf} / \mathrm{stb}$, identifying three GOR classes with the median GORs of 200, 500, and $1300 \mathrm{scf} / \mathrm{stb}$.

- As far as we can tell, EIA selects all wells, including gas condensate and gas wells.

- We select wells with at least 6 months of production in contrast to the EIA's criterion of at least three months on production.

- Almost all oil wells in the Eagle Ford have aggregated production records. We use our own, mass-conserving but painful procedure for the record disaggregation. We don't know what EIA did.

- We use a physics-based model of production and shut off wells when their production is less than 10 boe/day, while EIA uses hyperbolic decline curves and extrapolates them to 30 years. In this case, hyperbolic decline extrapolations always overestimate well EURs.

- Table 2 shows that our EURs for the black-oil wells in the six counties in which EIA reported their results bear little correlation with the EIA's EURs; three are lower and three are higher.

- Nevertheless, to two significant digits, both sets of EURs have identical averages. This agreement could be a fortuitous coincidence, because one would expect the EIA estimate to be higher.

\section{Acknowledgements}

This work was supported by the baseline and center funding at the Ali I. Al-Naimi Center for Petroleum Engineering Research (ANPERC) at the King Abdullah University of Science \& Technology (KAUST) in the Kingdom of Saudi Arabia.

We would like to thank Dr. Arthur Berman of Labyrinth Consulting Services, Inc. in Houston, Texas, for pointing out the multitudinous problems with allocation of oil well production in Texas, and working through a difficult example in DrillingInfo with Wardana and Wissem. Art visited us in November 2016. 
Table 2: Our EURs for the Eagle Ford shale black oil wells compare well with EIA's 2014 Annual Energy Outlook by D. Van Wagener

\begin{tabular}{|c|c|c|c|c|c|}
\hline \multirow[b]{2}{*}{ County } & \multicolumn{3}{|c|}{ SPE 187226 Predictions } & \multicolumn{2}{|c|}{ EIA's Energy Outlook 2014* } \\
\hline & EUR (bbls) & $\begin{array}{c}\text { Number of } \\
\text { Wells }\end{array}$ & $\begin{array}{c}\text { Average EUR } \\
\text { (bbls/well) }\end{array}$ & $\begin{array}{c}\text { Number of } \\
\text { Wells }\end{array}$ & $\begin{array}{c}\text { Average EUR } \\
\text { (bbls/well) }\end{array}$ \\
\hline Atascosa & $67,219,000$ & 377 & 178,000 & - & - \\
\hline Bastrop & 176,000 & 1 & 176,000 & - & . \\
\hline Brazos & $6,428,000$ & 47 & 137,000 & - & . \\
\hline Burleson & $6,412,000$ & 49 & 131,000 & - & - \\
\hline Caldwell & 116,000 & 5 & 23,000 & - & - \\
\hline Dewitt & $8,914,000$ & 42 & 212,000 & 453 & 334,000 \\
\hline Dimmit & $3,915,000$ & 45 & 87,000 & 820 & 137,000 \\
\hline Fayette & $8,482,000$ & 53 & 160,000 & - & - \\
\hline Frio & $29,871,000$ & 203 & 147,000 & - & 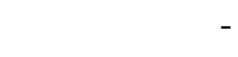 \\
\hline Gonzales & $54,211,000$ & 329 & 165,000 & 486 & 198,000 \\
\hline Karnes & $105,634,000$ & 446 & 237,000 & 975 & 226,000 \\
\hline Lasalle & $67,089,000$ & 329 & 204,000 & 755 & 153,000 \\
\hline Lavaca & $3,794,000$ & 28 & 135,000 & - & - \\
\hline Lee & $3,040,000$ & 40 & 76,000 & - & - \\
\hline Leon & 389,000 & 6 & 65,000 & - & - \\
\hline Live Oak & $15,332,000$ & 96 & 160,000 & - & - \\
\hline Madison & 378,000 & 4 & 94,000 & - & - \\
\hline Maverick & 24,000 & 2 & 12,000 & 10 & 25,000 \\
\hline Mcmullen & $22,990,000$ & 172 & 134,000 & 455 & 127,000 \\
\hline Milam & 19,000 & 1 & 19,000 & - & - \\
\hline Robertson & $1,335,000$ & 13 & 103,000 & - & - \\
\hline Titus & $1,401,000$ & 27 & 52,000 & - & - \\
\hline Wilson & $11,911,000$ & 99 & 120,000 & - & - \\
\hline Wood & $2,112,000$ & 25 & 84,000 & - & - \\
\hline Zavala & $16,006,000$ & 172 & 93,000 & - & - \\
\hline Total/Mean & $437,198,000$ & 2,611 & 167,000 & 3,954 & $171,000^{*}$ \\
\hline
\end{tabular}

* The study by EIA (2014) covered 32 counties in Texas with 5,384 wells, whose mean EUR was 168,000 bbl. However, data from just seven counties have been reported. 


\section{Figures}

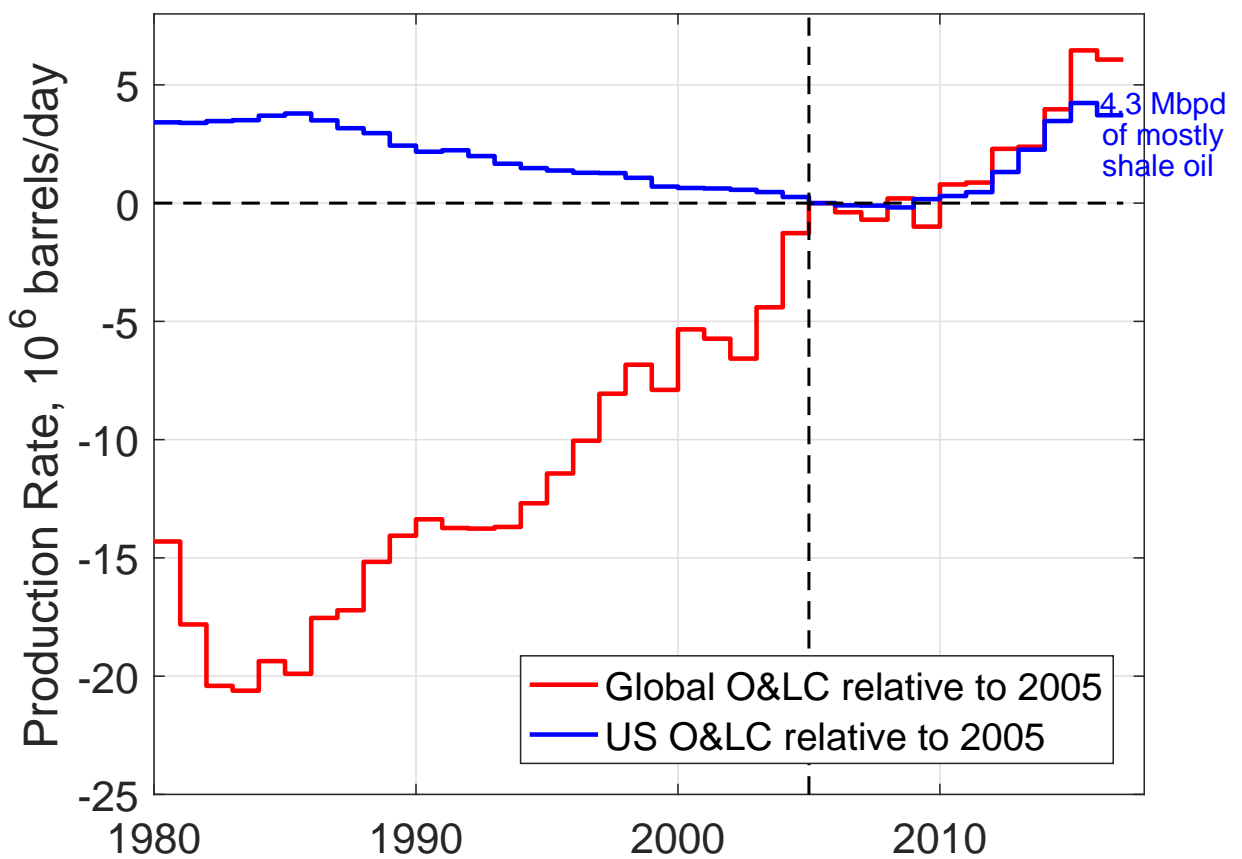

Figure 1: Increases of production of crude oil \& lease condensate worldwide and in the U.S. relative to Jan 2005. In October 2004, global production stopped growing for six years and then increased exactly as oil production in the U.S. This means that all new petroleum projects in the world cancelled production declines, even with the highest E\&P investment ever. Source: U.S. DOE EIA, accessed 01/18/2017. 

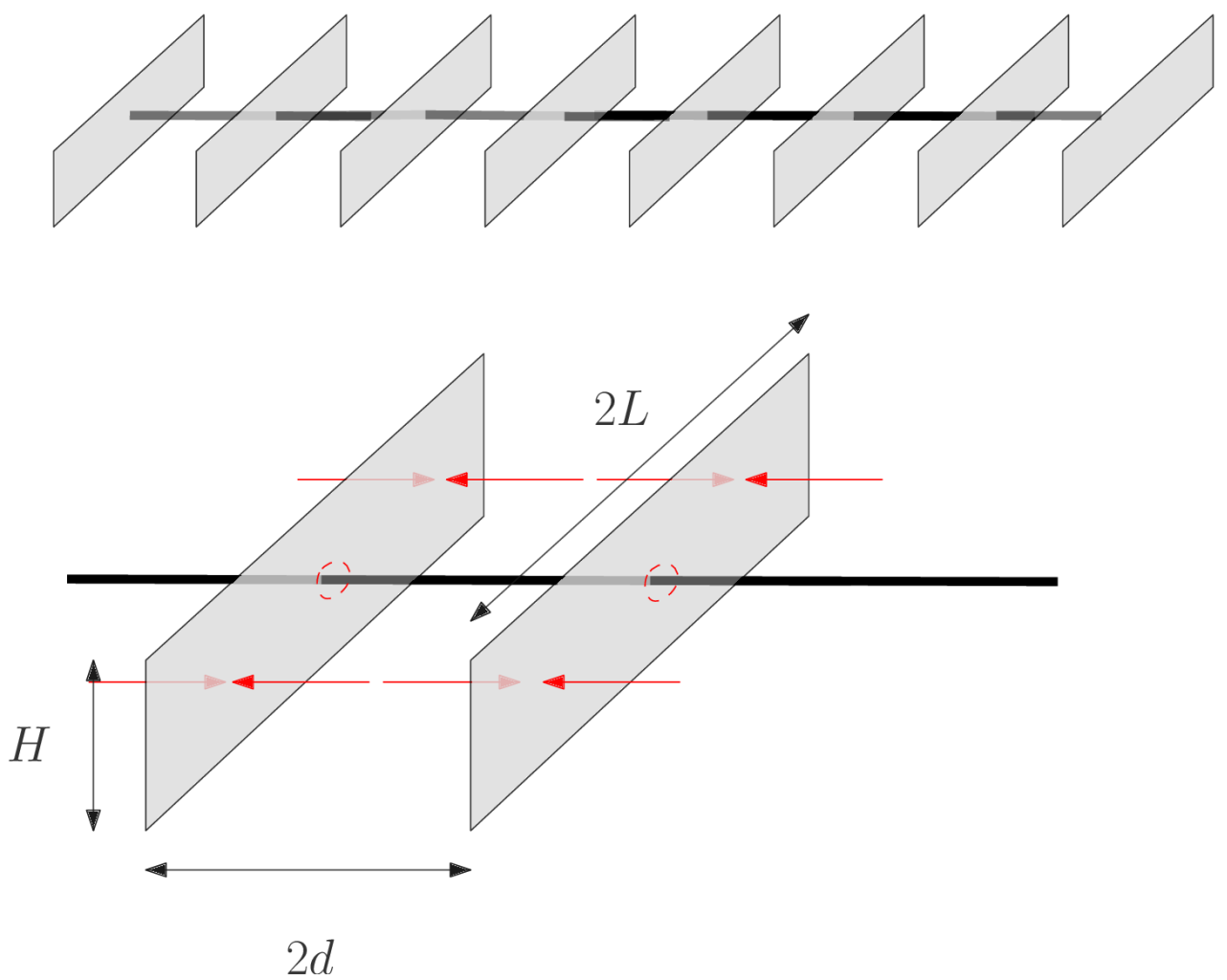

Figure 2: A horizontal well with 10-20 hydrofracture "stages," spaced uniformly along its entire length. There is one equivalent hydrofracture per stage. The common hydrofracture height is $H$ and the tip-to-tip length of each fracture is $2 L$. The distance between between the hydrofractures is $2 d$. The exterior hydrofractures at the left- and right-hand end of the well drain the reservoir volume beyond the volume spanned by these hydrofractures and the length of the lateral. The hydrofractures are perpendicular to the wellbore. The flow of oil and gas (red arrows) is horizontal and perpendicular to the fracture planes. Once inside the hydrofracture, the fluids flows more or less radially into the well perforations connected to each hydrofracture. The permeability of a propped hydrofracture is infinite in comparison with the effective permeability of the rock matrix and natural fractures feeding the fluids into this hydrofracture. 


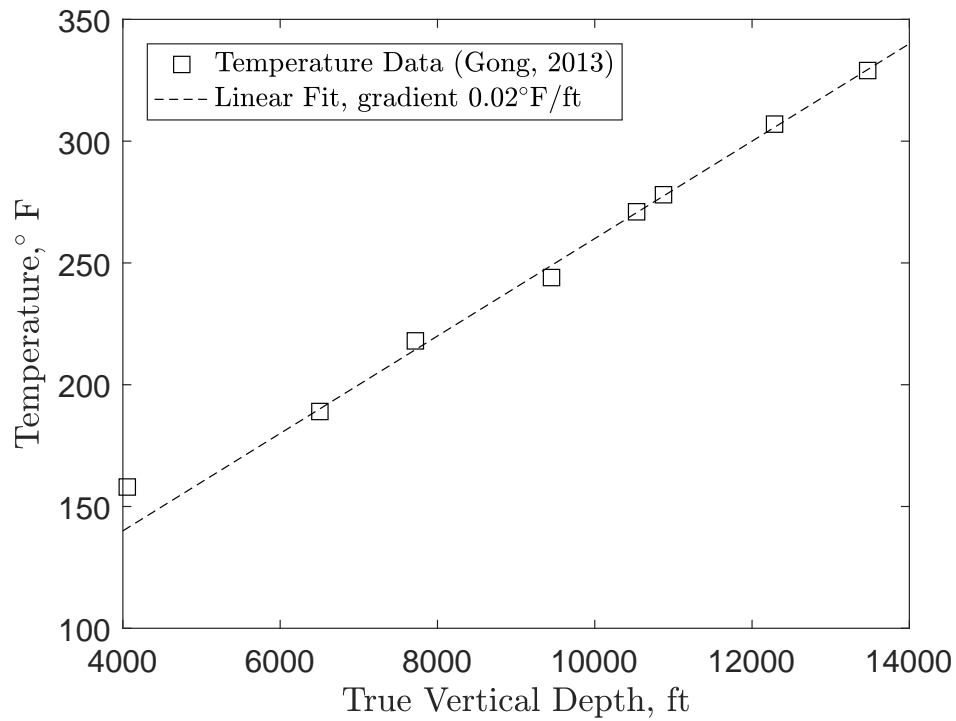

Figure 3: Rock temperature as a function of depth. Data source: Gong (2013).

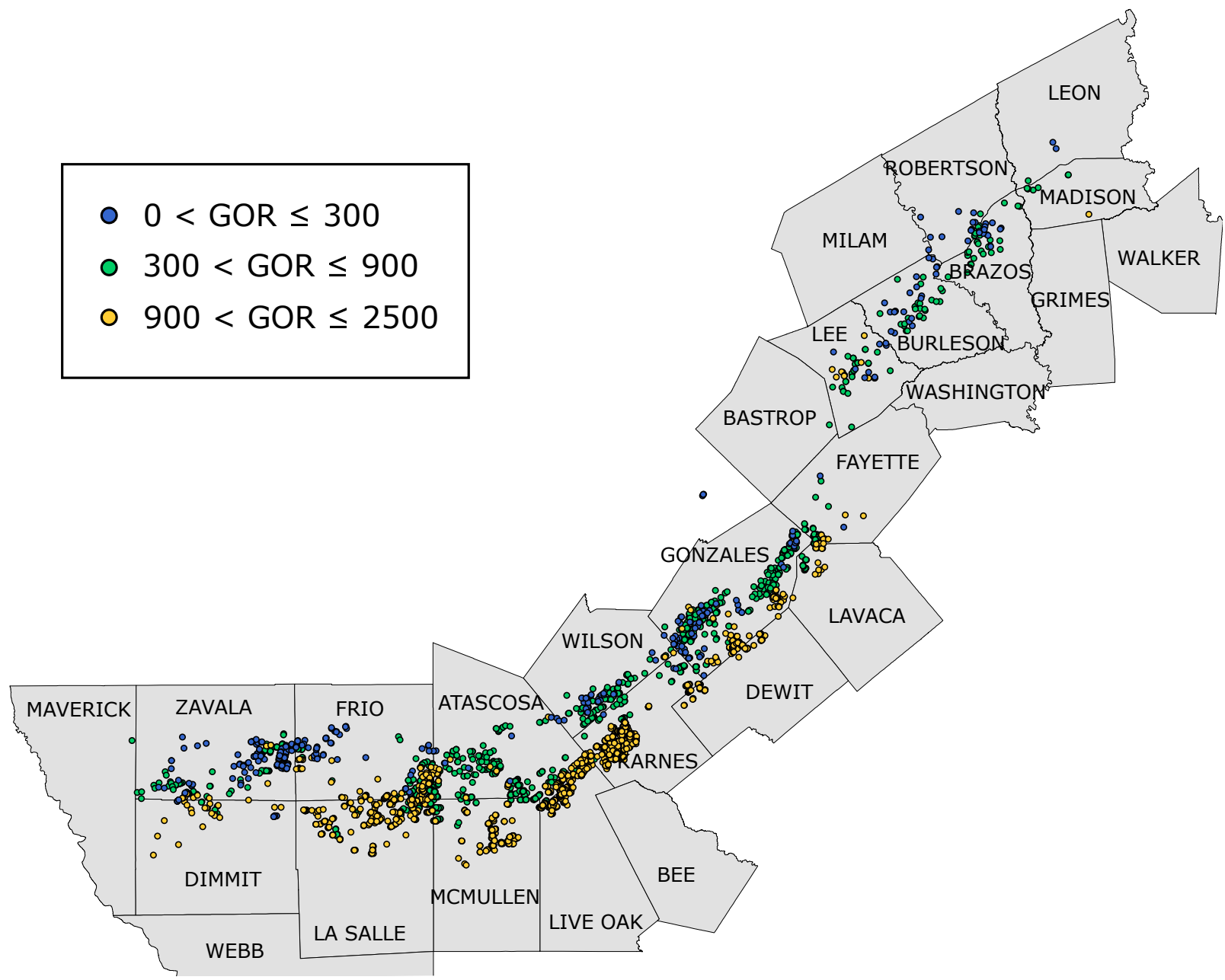

Figure 4: The black oil wells in Eagle Ford align nicely with the dip, becoming more condensate-like downdip to the S-SE. There are 2,611 wells with three GOR classes (1,123 leases) that qualify for further analysis. 


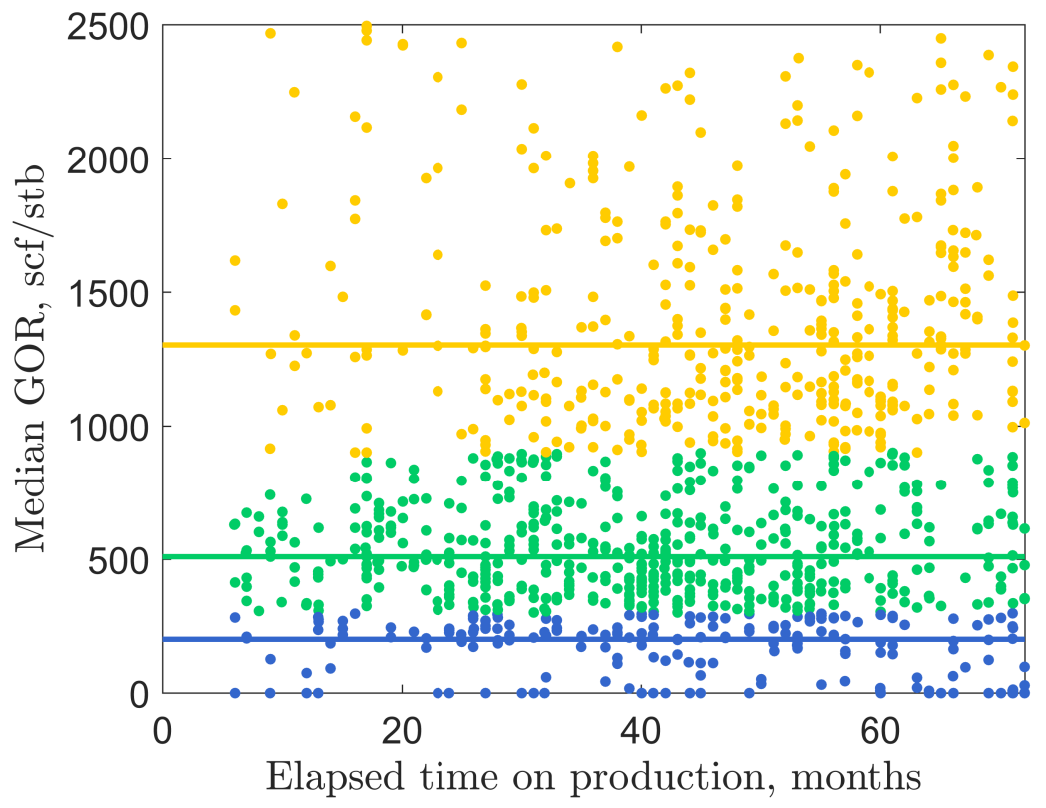

Figure 5: Three classes of cumulative GORs were identified for further analysis. The horizontal lines are medians of each class. From bottom to top, these median GORs are approximately 300,500 , and 1300 scf/stb, respectively. Note that wells with fewer than six months on production have been rejected.

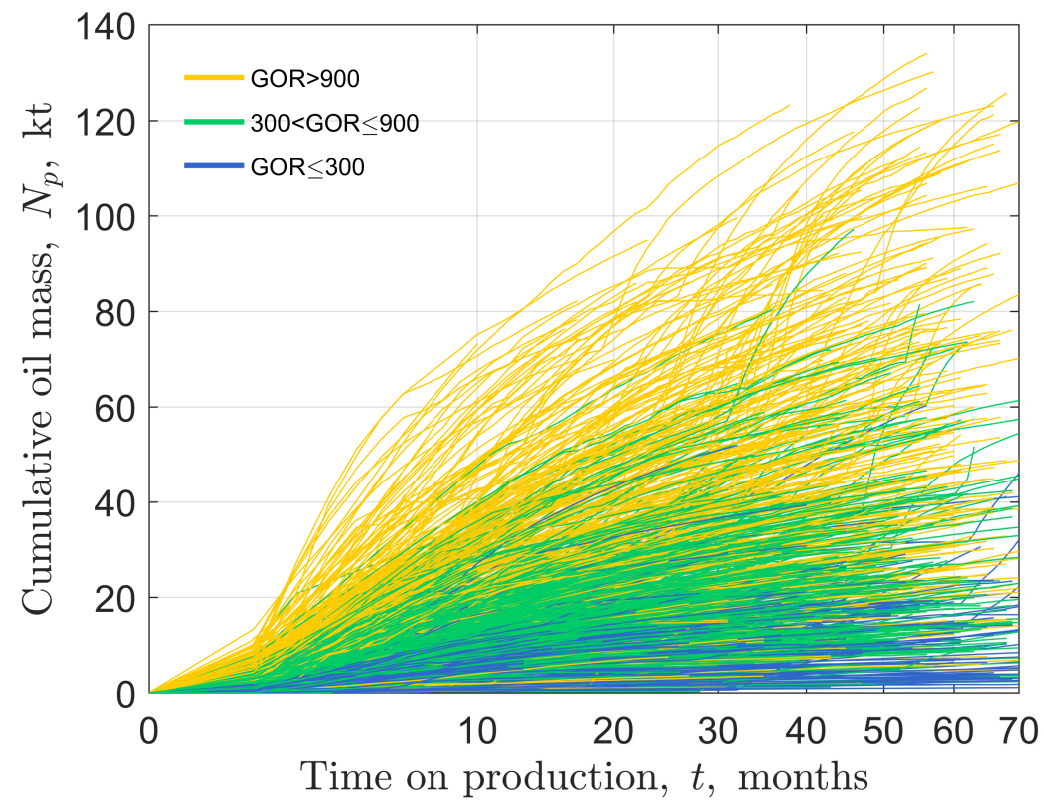

Figure 6: The cumulative mass of stock tank oil plus stock tank gas allocated from 1,123 selected leases (equivalent to 2,611 wells). Note that some of the wells with the highest GOR are outliers in terms of oil and gas production. The median well produces $7.8 \mathrm{kt}$ of total mass for GOR $\leq 300 \mathrm{scf} / \mathrm{stb}$. The other two classes of wells produce 2.09 and 3.97 times more mass, respectively. Therefore, gas production is an important component of total mass produced, ranging from $23 \%$ of the mass of oil for GOR $\leq 300$ scf/stb to $150 \%$ for GOR $>900$ scf/stb. 


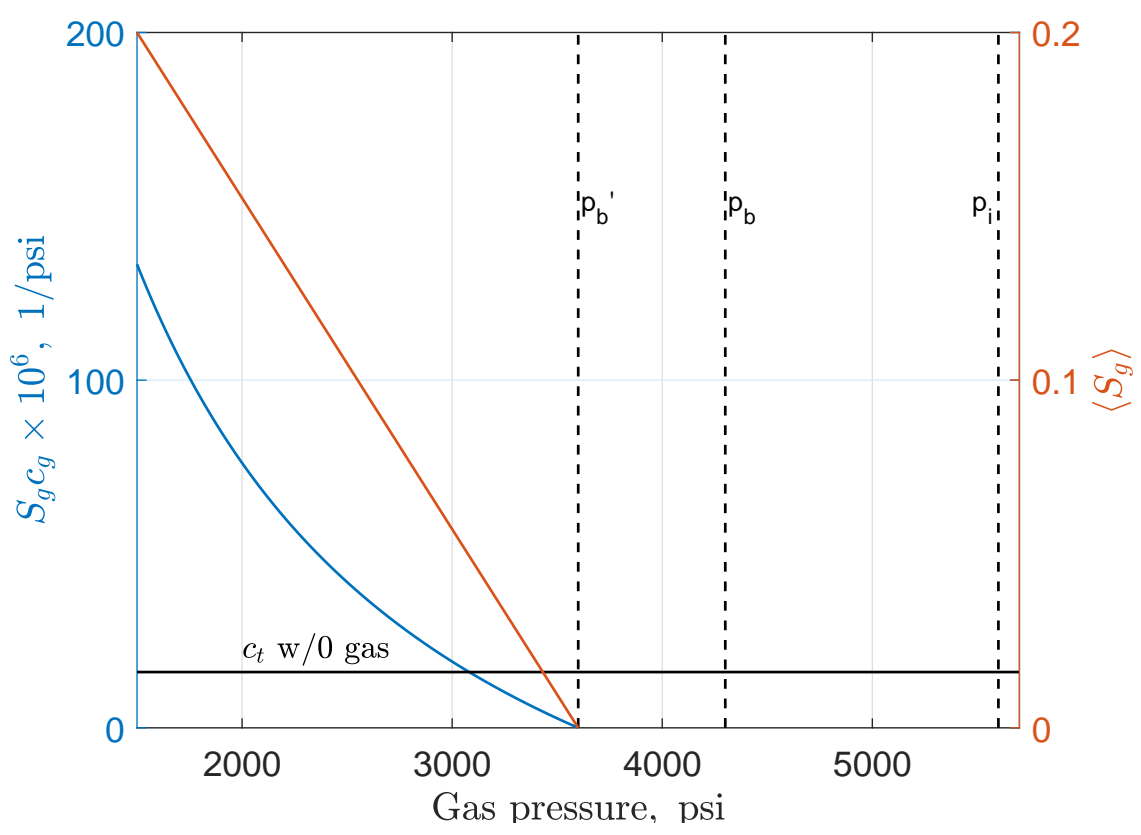

Figure 7: Assuming that average gas saturation increases linearly with a decrease of average reservoir pressure below the adjusted bubble, $P_{b}^{\prime}$, point (red curve), the resulting gas compressibility (blue curve) dominates the overall system compressibility. The total compressibility of oil, water and pore space is shown as the black line.

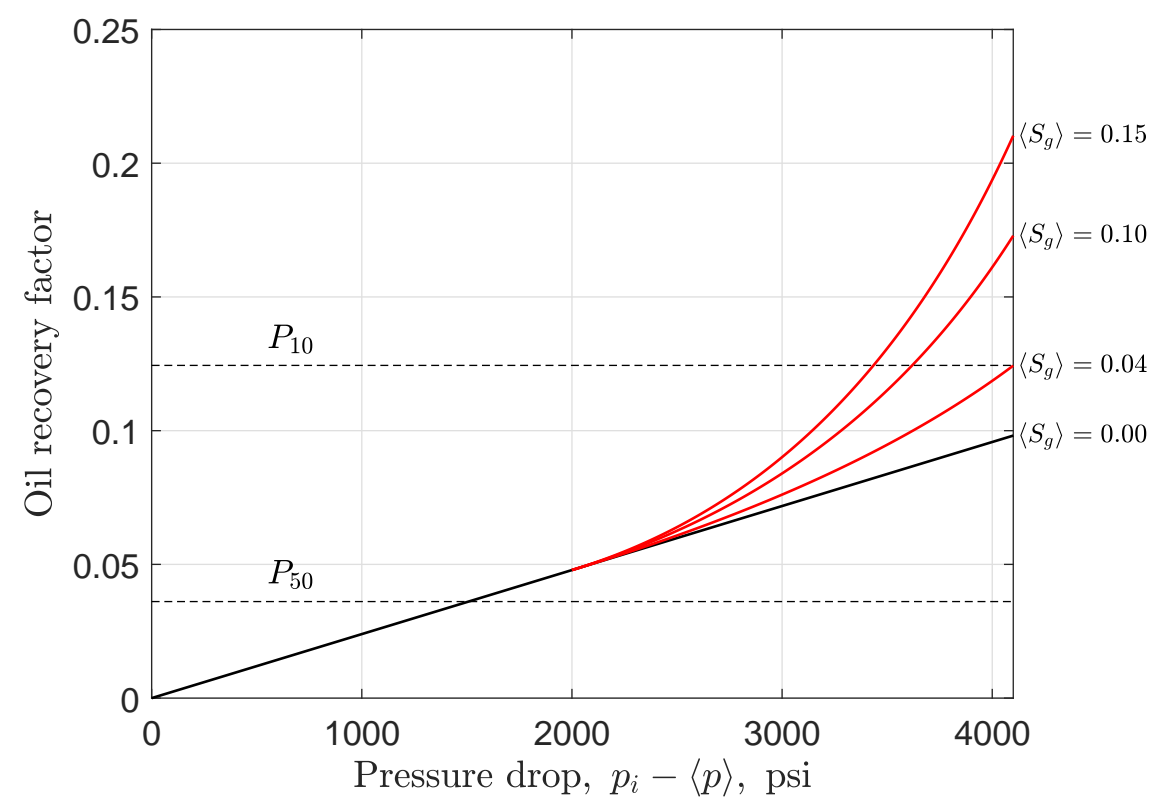

Figure 8: Integration of the total compressibility under the assumption that average gas saturation never builds above the critical value, $S_{g c}$. Above bubble point, RF is proportional to the liquid and pore space compressibility multiplied by the pressure drop $\Delta p=p_{i}-\langle p\rangle$. Below bubble point, gas compressibility kicks in under the assumption that average gas saturation $\left\langle S_{g}\right\rangle \in\left[0, S_{g c}\right]$ increases linearly with the decreasing reservoir pressure, and gas compressibility is $c_{g} \approx 1 / p$. 


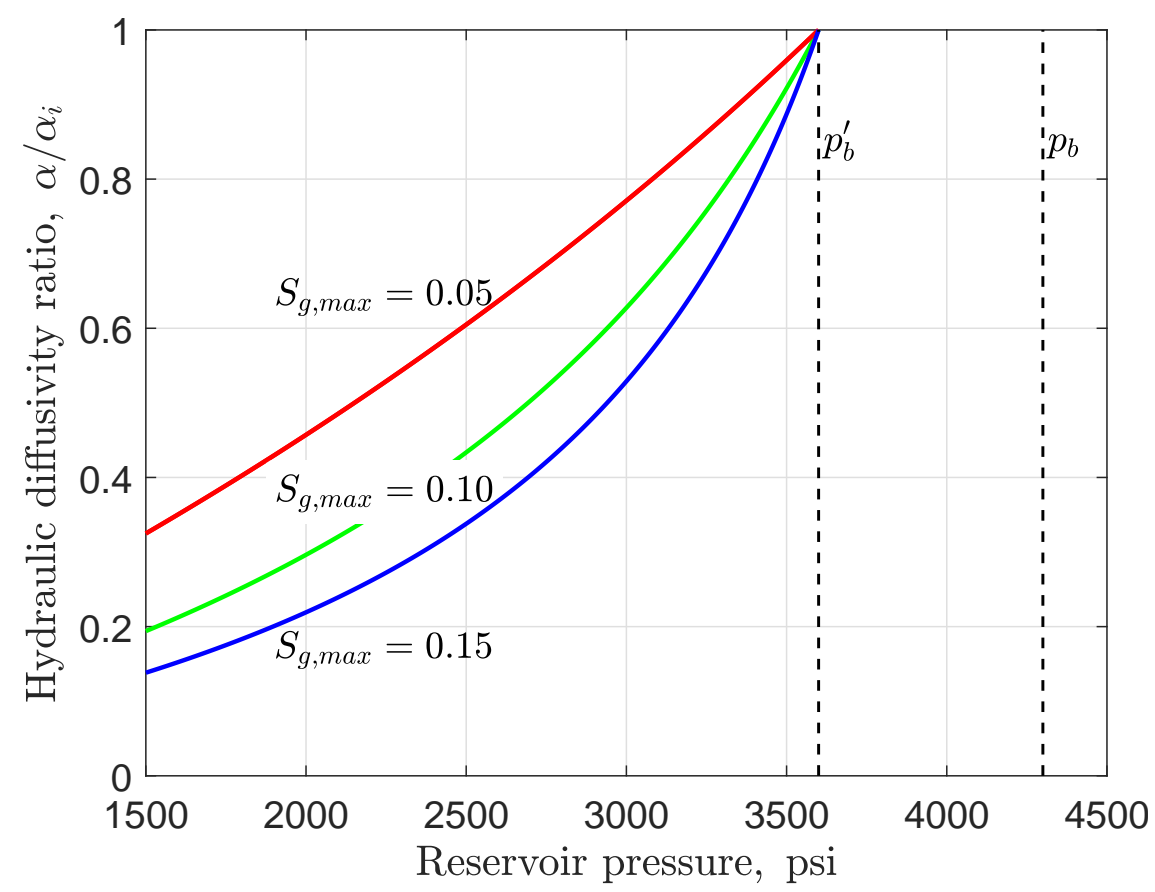

Figure 9: The ratio of hydraulic diffusivity at a reservoir pressure $p$ to that at the initial reservoir pressure $p_{i}>p_{b}$. The maximum average saturation of gas bubbles trapped in the pore space is assumed to be 5,10 , and $15 \%$.

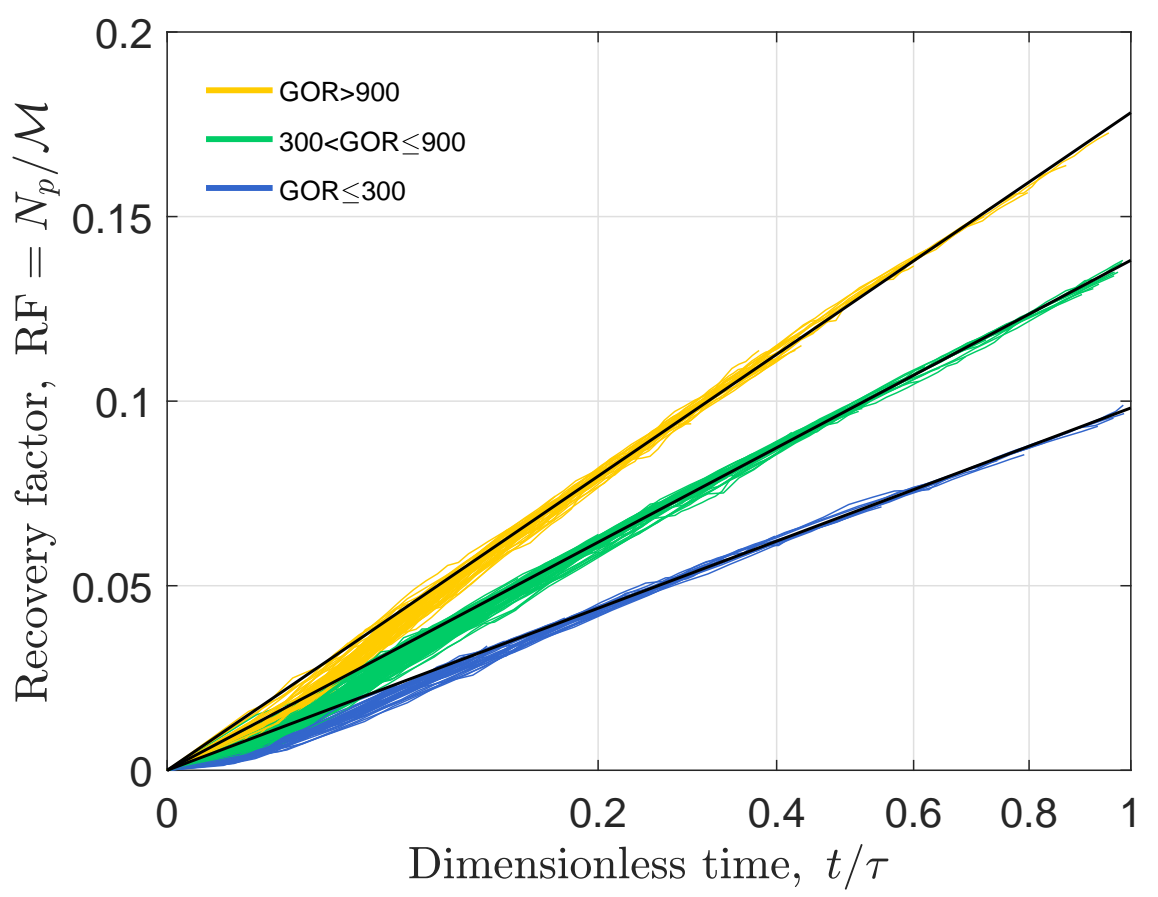

Figure 10: 429 allocated wells in 268 leases are still in early time flow, with cumulative production vs. square root of time plotting as straight lines, one for each GOR class. Note that the $x$-scale in this plot is the square root of time on production, but the nonlinearly distributed labels are the corresponding times. 


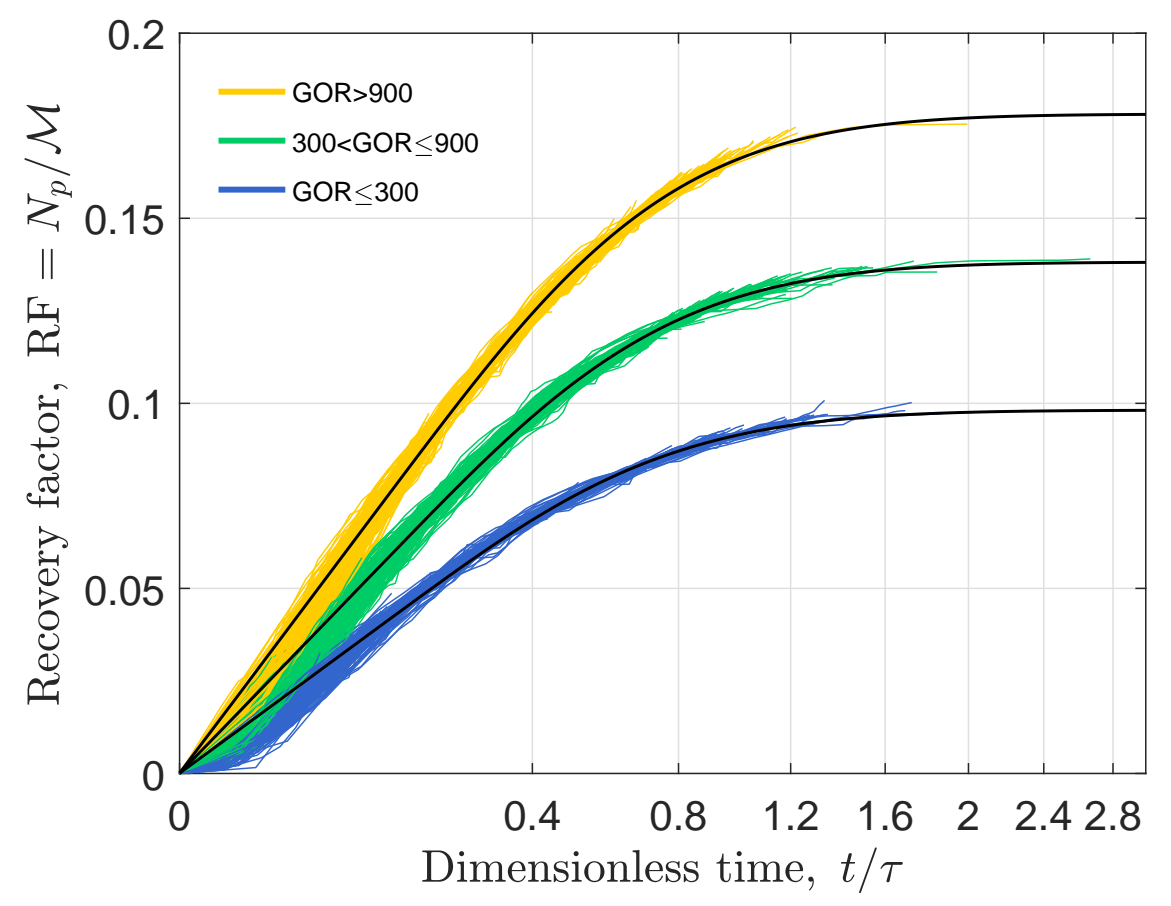

Figure 11: 2,182 allocated wells in 855 leases have already pressure-interfered and their cumulative production bends down when plotted vs. square root of time.
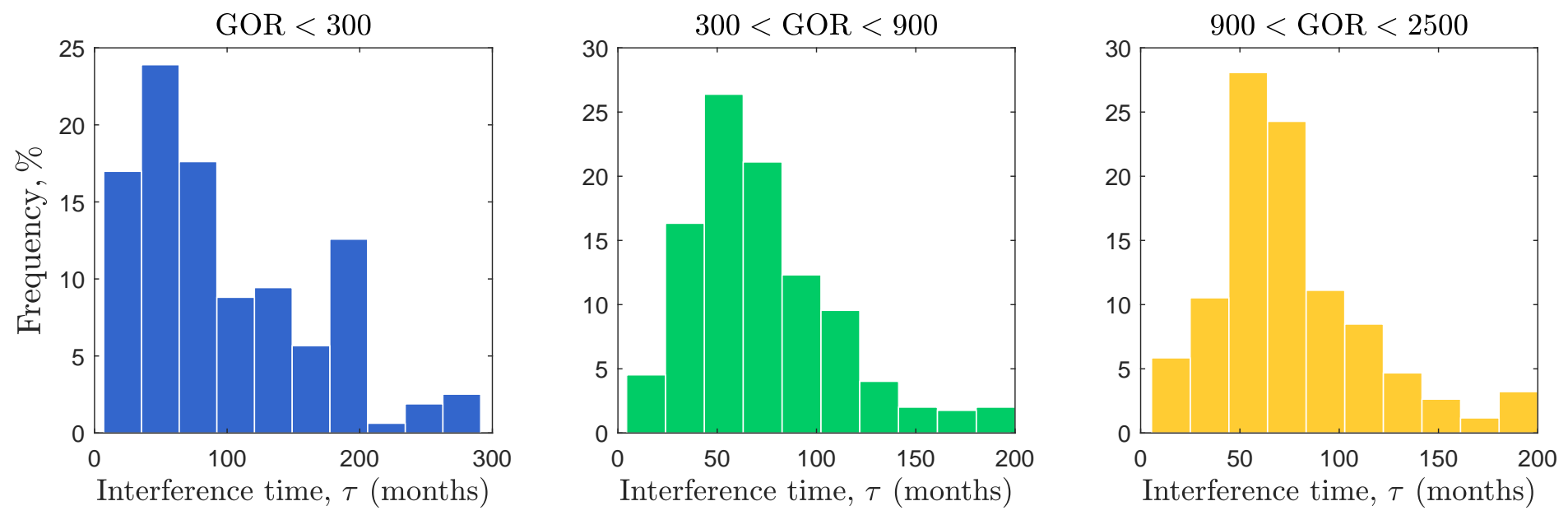

Figure 12: Frequency distributions of interference times in wells with inter-hydrofracture pressure interference. Note that the tail values of $\tau$ above 120 months are increasingly uncertain. 


\section{References}

Carslaw, H. S., and J. C. Jaeger, Conduction of Heat in Solids, $2^{\text {nd }}$ ed., Clarendon Press, Oxford, 1959.

EIA, U., Annual Energy Outlook. DOE/EIA-0383, 2014.

Gong, X., Assessment of eagle ford shale oil and gas resources, Ph.d. thesis, Texas A\&M, College Station, 2013.

Honarpour, M. M., N. R. Nagarajan, A. Orangi, F. Arasteh, and Z. Yao, SPE 158042-MS: Characterization of Critical Fluid PVT, Rock, and Rock-Fluid Properties - Impact on Reservoir Performance of Liquid Rich Shales, in SPE Annual Technical Conference and Exhibition, SPE, San Antonio, TX, 2004.

Jin, G., T. W. Patzek, and D. Silin, SPE 90084-MS: Direct Prediction of the Absolute Permeability of Unconsolidated and Consolidated Reservoir Rock, in SPE Annual Technical Conference and Exhibition, SPE, Houston, TX, 2004.

Orangi, A., N. R. Nagarajan, M. M. Honarpour, and J. J. Rosenzweig, SPE 140536-MS: Unconventional Shale Oil and Gas-Condensate Reservoir Production, Impact of Rock, Fluid, and Hydraulic Fracture, in SPE Hydraulic Fracturing Technology Conference and Exhibition, SPE, Woodlands, TX, 2011.

Patzek, T., F. Male, and M. Marder, A simple model of gas production from hydrofractured horizontal wells in shales, $A A P G$ Bulletin, 98(12), 2507 - 2529, 2014.

Patzek, T. W., F. Male, and M. Marder, Gas production in the Barnett Shale obeys a simple scaling theory, Proceedings of the National Academy of Sciences, 110(49), 19,731 - 19,736, doi:10.1073/pnas.1313380110, 2013.

Tainter, J. A., and T. W. Patzek, Drilling Down: The Gulf Oil Debacle and Our Energy Dilemma, Springer Verlag, New York, 2011. 


\section{Appendix A: Overall Mass and Momentum Balance for Single-Phase Flow in a Slightly Compressible Fluid/Rock System}

The fluids consist of oil that flows, as well as water and gas that don't. The fluids form three immiscible phases. The oil is surrounded with immovable water that lines pore corners, and nooks and crannies in the pore walls. At a low enough local pressure, stationary gas bubbles evolve in the oil. The fluids are compressible and rock's solid skeleton is slightly compressible. We set out to derive an approximate equation governing the single-phase flow of oil above and somewhat below the oil's bubble pressure. The result is a nonlinear pressure diffusion equation with an appropriately defined hydraulic diffusivity.
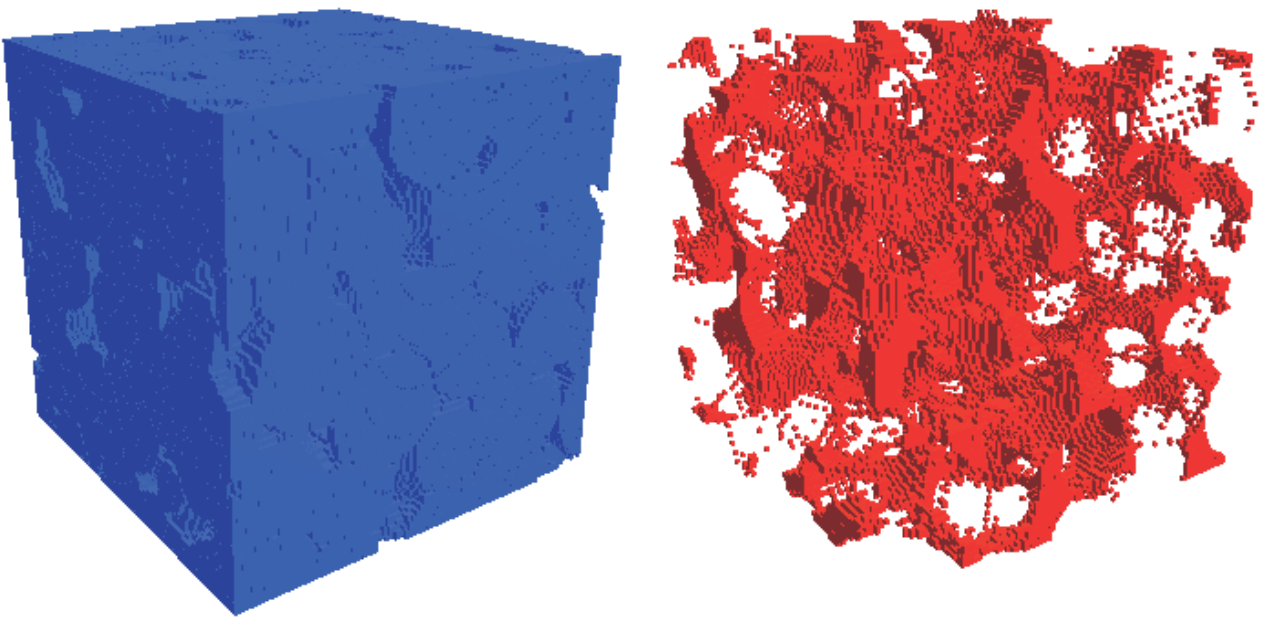

Figure A1: At the reference state, we imagine a colored rock grain sample, in blue, filled with colored fluid, in red. First, we remove the red fluid into a beaker and fill the pore space with ordinary fluid. Second, we change the stress on the solid and the pore pressure, and "measure" the new pore volume, $V_{\phi}$. Third, we measure the new red fluid volume under the new pore pressure, $V_{\text {fluid. }}$ In general, the new pore volume and fluid volume will not be equal to each other, and the fluid will have to flow in/out of the blue rock volume. Image source: Jin et al. (2004).

Volumetric Fluid Content. The density of the fluid mass $m_{\text {fluid }}$ occupying the volume $V_{\text {fluid }}$ in a beaker is

$$
\rho_{\text {fluid }}=\frac{m_{\text {fluid }}}{V_{\text {fluid }}}
$$

The bulk density of the fluid inside a porous rock is

$$
\rho_{b}=\frac{m_{\text {fluid }}}{V}=\left(\frac{V_{\text {fluid }}}{V}\right)\left(\frac{m}{V_{\text {fluid }}}\right)=\phi \rho_{\text {fluid }}
$$

At an arbitrary reference or initial condition, the fluid mass in the pore space is $m_{\text {fluid, },}$, and the initial fluid volume, $V_{\text {fluid, } 0}$, is equal to the initial pore space volume, $V_{\phi 0}$. The initial bulk volume of the rock is $V_{0}$.

We apply stress on the solid skeleton and change the fluid pressure at the same time, see Fig. A1. Both the fluid volume, $V_{f}$, and the pore space volume, $V_{\phi}$, will change. In the end, the new pore space volume will be filled entirely with the fluid at the new fluid pressure and the new fluid density. But, initially, we can think about these two volume changes independently, and then introduce flow into or from the rock pore space to arrive at the final state. At the new state we can write formally

$$
m_{\text {fluid }}=m_{\text {fluid }, 0} \frac{V_{\phi}}{V_{\text {fluid }}}
$$


After Biot, we will now introduce the increment of fluid mass per unit initial bulk volume $V_{0}$, normalized by the initial fluid density $\rho_{\text {fluid }, 0}=m_{\text {fluid }, 0} / V_{\text {fluid }, 0}$ :

$$
\delta \zeta:=\frac{\delta m_{\text {fluid }} / V_{0}}{m_{\text {fluid }, 0} / V_{\text {fluid }, 0}}=\frac{\delta \rho_{b f}}{\rho_{\text {fluid }, 0}}=\left(\frac{V_{\text {fluid }, 0}}{V_{0}}\right) \delta\left(\frac{V_{\phi}}{V_{\text {fluid }}}\right)=\frac{V_{\text {fluid }, 0}}{V_{0}} \frac{\delta V_{\phi} V_{\text {fluid }, 0}-\delta V_{\text {fluid }} V_{\phi 0}}{V_{\text {fluid }, 0}^{2}}
$$

But, by assumption, $V_{\text {fluid, } 0}=V_{\phi 0}$, and the initial fluid volume and the pore space volume cancel out.

Therefore, the increment of fluid content, i.e., the difference between the fractional change of pore volume and the fractional change in fluid volume is

$$
\delta \zeta=\frac{1}{V_{0}}\left(\delta V_{\phi}-\delta V_{\text {fluid }}\right)
$$

Let's keep the confining pressure, $p_{c}$, constant and only change the fluid pressure, $p$, see Fig. A2. If the fluid is incompressible, i.e., when $\delta V_{\text {fluid }}=0$, the increment of fluid content is

$$
\delta \zeta=\frac{\delta V_{\phi}}{V_{0}}=\frac{V_{\phi 0}}{V_{0}}\left(\frac{1}{V_{\phi 0}} \frac{\delta V_{\phi}}{\delta p}\right)_{p_{c}} \delta p=\phi_{0} c_{\phi} \delta p \approx \phi c_{\phi} \delta p
$$

Note that the approximate equality above underscores that the bulk volume and the pore space volume change simultaneously, and the porosity depends on both.

If, conversely, the fluid-filled pore space is incompressible

$$
\delta \zeta=\frac{V_{\text {fluid }, 0}}{V_{0}}\left(-\frac{1}{V_{\text {fluid }, 0}} \frac{\delta V_{\text {fluid }}}{\delta p}\right) \delta p=\phi_{0} c_{\text {fluid }} \delta p \approx \phi c_{\text {fluid }} \delta p
$$

One can impose a constant load on the piston and the side jacket (a hydrostatic stress, $S_{1}=S_{2}=S_{3}=S$, or the confining pressure $p_{c}=S$ ) in the apparatus shown in Figure A2, and change (increase or decrease) the fluid pressure independently through the hollow piston. In this case, the bulk isothermal compressibility at constant stress and with simultaneous fluid flow will be:

$$
c_{p_{c}}=\left(\frac{\delta \zeta}{\delta p}\right)_{p_{c}, T} \approx\left(\frac{\partial \zeta}{\partial p}\right)_{p_{c}, T}
$$

where the parameters held constant are the confining pressure, $p_{c}$, and the temperature, $T$. From Eqs. (A8), (A6), and (A7), it follows immediately that when both the fluid and the pore space are somewhat compressible

$$
c_{p_{c}} \approx \phi\left(c_{\text {fluid }}+c_{\phi}\right)
$$

Suppose now that the blue fluid in the pore space is actually made up of three immiscible fluids: Flowing oil with the density $\rho_{o}$ and saturation $S_{o}$, practically immovable water with the density of $\rho_{w}$ and saturation $S_{w}$, and bubbles of gas with the density $\rho_{g}$ and saturation $S_{g}$. The thermodynamic reservoir pressure, $p$, is the oil pressure, since gas is disconnected. The volume-fraction weighted bulk density of the pore fluid that consists of three immiscible phases is:

$$
\rho_{\text {fluid }, b}=\phi\left(S_{o} \rho_{o}+S_{w} \rho_{w}+S_{g} \rho_{g}\right), \quad \frac{\mathrm{kg}}{\mathrm{m}^{3} \text { bulk }}
$$

The overall mass balance of the bulk fluid in the pore space is

$$
\frac{\partial \rho_{\text {fluid }, b}}{\partial t}=-\nabla \cdot\left(\rho_{o} u_{o}+\rho_{w} u_{w}+\rho_{g} u_{g}\right)=-\nabla \cdot \rho_{o} u_{o}, \quad \frac{\mathrm{kg}}{\mathrm{m}^{3} \text { bulk-s }}
$$

because neither water nor gas flow. Here $u_{o}$ is the superficial (Darcy) velocity of oil. 


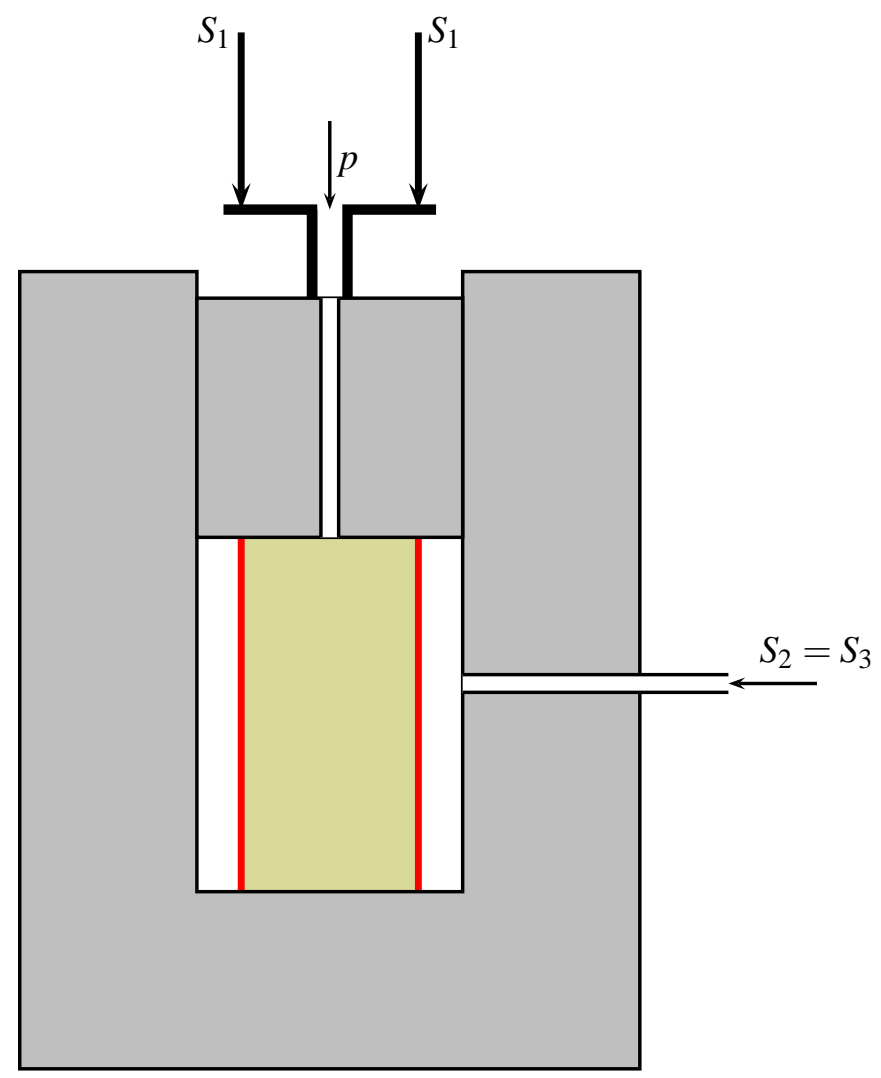

Figure A2: The jacketed triaxial rock compressibility measurement. The vertical stress, $S_{1}$, is applied to a hollow piston. The tube in the piston is used to regulate the pore pressure, $p$. The lateral stresses, $S_{2}=S_{3}$, are applied to the copper-jacketed specimen by injecting oil through the side tube. The confining pressure is defined as $p_{c}=\frac{1}{3}\left(S_{1}+S_{2}+S_{3}\right)$.

Using Eqs. (A4), (A8) - (A10), we obtain:

$$
\begin{aligned}
\frac{\partial \rho_{\text {fluid }, b}}{\partial t} & =\rho_{\text {fluid }, 0}(\underbrace{\frac{1}{\partial p}}_{\rho_{\text {fluid }, 0}})_{p_{c}, T} \frac{\partial \rho_{\text {fluid }, b}}{\partial t}=\rho_{\text {fluid }, 0} c_{p_{c}} \frac{\partial p}{\partial t} \approx \rho_{\text {fluid }, 0} \phi\left(c_{\text {fluid }}+c_{\phi}\right) \frac{\partial p}{\partial t} \\
& =\rho_{\text {fluid }, 0} \phi(\underbrace{S_{o_{o} c_{o}+S_{w} c_{w}+S_{g} c_{g}}}_{=c_{\text {fluid }}}+c_{\phi}) \frac{\partial p}{\partial t}=\rho_{\text {fluid }, 0} \phi c_{t} \frac{\partial p}{\partial t}
\end{aligned}
$$

Now we insert into the right hand side of Eq. (A11) Darcy's law for horizontal flow of oil, and make an argument that the quantity

$$
\nabla\left(\frac{\rho_{o}}{\mu_{o}}\right) \cdot \nabla p
$$

is small in the second order. Here $k$ is the rock permeability and $\mu_{o}$ the oil viscosity. The result is:

$$
\frac{\partial p}{\partial t}=\left(\frac{k}{\phi c_{t} \mu_{o}}\right)\left(\frac{\rho_{o}}{\rho_{\text {fluid }, 0}}\right) \nabla^{2} p
$$

We define the hydraulic diffusivity of pressure for the slightly compressible horizontal flow of oil in the presence of immovable water and some gas as

$$
\alpha \equiv\left(\frac{k}{\phi c_{t} \mu_{o}}\right)\left(\frac{\rho_{o}}{\rho_{\text {fluid }, 0}}\right)
$$

If there is enough gas as compressible bubbles, $\alpha$ becomes a function of reservoir pressure. 
Table A1: Typical values of key fluid parameters.

\begin{tabular}{|c|c|c|c|c|}
\hline Parameter & SI units ${ }^{a}$ & Field units ${ }^{a}$ & SI units ${ }^{b}$ & Field units $^{b}$ \\
\hline Oil compressibility, $c_{o}$ & $2.13 \times 10^{-9} \mathrm{~Pa}^{-1}$ & 15 microsips $\left(10^{-6} \mathrm{psi}^{-1}\right)$ & & \\
\hline Water compressibility, $c_{w}$ & $4.27 \times 10^{-10} \mathrm{~Pa}^{-1}$ & 3 microsips $\left(10^{-6} \mathrm{psi}^{-1}\right)$ & & \\
\hline Oil viscosity, $\mu_{o, i}$ & & & $5.8 \times 10^{-5} \mathrm{~Pa} \mathrm{~s}$ & $0.58 \mathrm{cp}$ \\
\hline Oil FVF ${ }^{c} B_{o, i}$ & $1.65^{d} \mathrm{~m}^{3} / \mathrm{sm}^{3}$ & $1.65^{d} \mathrm{rbbl} / \mathrm{stb}$ & $1.34 \mathrm{~m}^{3} / \mathrm{sm}^{3}$ & $1.34 \mathrm{rbbl} / \mathrm{stb}$ \\
\hline Oil density/gravity & $958 \mathrm{~kg} / \mathrm{sm}^{3}$ & $41^{0} \mathrm{API}$ & $958 \mathrm{~kg} / \mathrm{sm}^{3}$ & $41^{0} \mathrm{API}$ \\
\hline Gas gravity, $\gamma_{g}$ & & & 0.905 & 0.905 \\
\hline $\mathrm{GOR}^{e}$ & $178 \mathrm{sm}^{3} / \mathrm{m}^{3}$ & $1000 \mathrm{scf} / \mathrm{stb}$ & $89 \mathrm{sm}^{3} / \mathrm{m}^{3}$ & $500 \mathrm{scf} / \mathrm{stb}$ \\
\hline Saturation pressure, $p_{b}$ & $30 \mathrm{MPa}$ & $4300^{f} \mathrm{psi}$ & $14.4 \mathrm{MPa}$ & $2053 \mathrm{psi}$ \\
\hline
\end{tabular}

${ }^{a}$ Data source: Gong (2013)

${ }^{b}$ Data source: Orangi et al. (2011)

${ }^{c}$ Formation volume factor

${ }^{d}$ From Orangi et al. (2011) for GOR=1000 oil

${ }^{e}$ Solution gas-oil ratio

${ }^{d} p_{b}=\sim 3250 \mathrm{psi}$ reported for a GOR=1000 scf/stb oil in Figure 2 in Orangi et al. (2011)

Table A2: Typical values of key reservoir and well parameters.

\begin{tabular}{|c|c|c|c|c|}
\hline Parameter & SI units ${ }^{a}$ & Field units ${ }^{a}$ & SI units ${ }^{b}$ & Field units ${ }^{b}$ \\
\hline Rock porosity, $\phi$ & 0.086 & 0.086 & & \\
\hline Rock permeability, $k$ & $0.1 \times 10^{-18} \mathrm{~m}^{2}$ & 0.1 microdarcy & & \\
\hline Rock compressibility, $c_{\phi}$ & $1.42 \times 10^{-10} \mathrm{~Pa}^{-1}$ & 1 microsip $\left(10^{-6} \mathrm{psi}^{-1}\right)$ & & \\
\hline Initial oil saturation, $S_{o i}$ & 0.67 & 0.67 & & \\
\hline Irreducible water saturation, $S_{w c}$ & 0.33 & 0.33 & & \\
\hline Initial pressure, $p_{i}$ & $36.7 \mathrm{MPa}$ & $5600 \mathrm{psi}$ & $44.3 \mathrm{MPa}$ & $6300 \mathrm{psi}$ \\
\hline Reservoir temperature, $T$ & $383 \mathrm{~K}$ & $230^{0} \mathrm{~F}$ & $387 \mathrm{~K}$ & $237^{0} \mathrm{~F}$ \\
\hline Fracture pressure $^{c}, p_{f}$ & $10.5 \mathrm{MPa}$ & $1500 \mathrm{psi}$ & & \\
\hline Horizontal well length, $L_{w}$ & $1500 \mathrm{~m}$ & $5000 \mathrm{ft}$ & & \\
\hline$\#$ of fracture stages, $N$ & 12 & 12 & & \\
\hline Fracture height, $H$ & $30 \mathrm{~m}$ & $100 \mathrm{ft}$ & & \\
\hline Tip-to-tip fracture length, $2 L$ & $400 \mathrm{~m}$ & $700 \mathrm{ft}$ & & \\
\hline
\end{tabular}

\footnotetext{
${ }^{a}$ Data source: Gong (2013)
}

${ }^{b}$ Data source: Orangi et al. (2011)

${ }^{c}$ The uniform fluid pressure in the hydrofractures 


\section{Appendix B: Decomposition of Lumped Production of Eagle Ford Oil Wells}

Texas Oil Tax Regulation and its Consequences. Evaluation of oil wells in the Eagle Ford is a challenge caused the rules of production reporting. The Texas Railroad Commission tax regulations for oil entities (Chapter 202) permit operators to report production from a variable number of wells as one lease production record. The operators may gather production from adjacent wells into well headers, connect these headers to a crude oil transmission pipeline, and report the total production from all lease wells as a single production record (bbl oil per month and GOR) based on the crude oil volumes delivered to the lease oil separation tanks and the total lease gas. It is therefore important to have a fast and consistent method of disaggregating lease production data back to individual allocated wells. In contrast, gas wells have individual wellhead production meters and are not aggregated.

Example of Extreme Lumping of Eagle Ford Lease Production. Fig. B1 shows 71 oil wells that are connected to the same pipeline and reported as one lease production record assigned to a well located at the border between the Dimmit and La Salle counties. The actual production data have been carefully tabulated and analyzed. We have found that these 71 wells

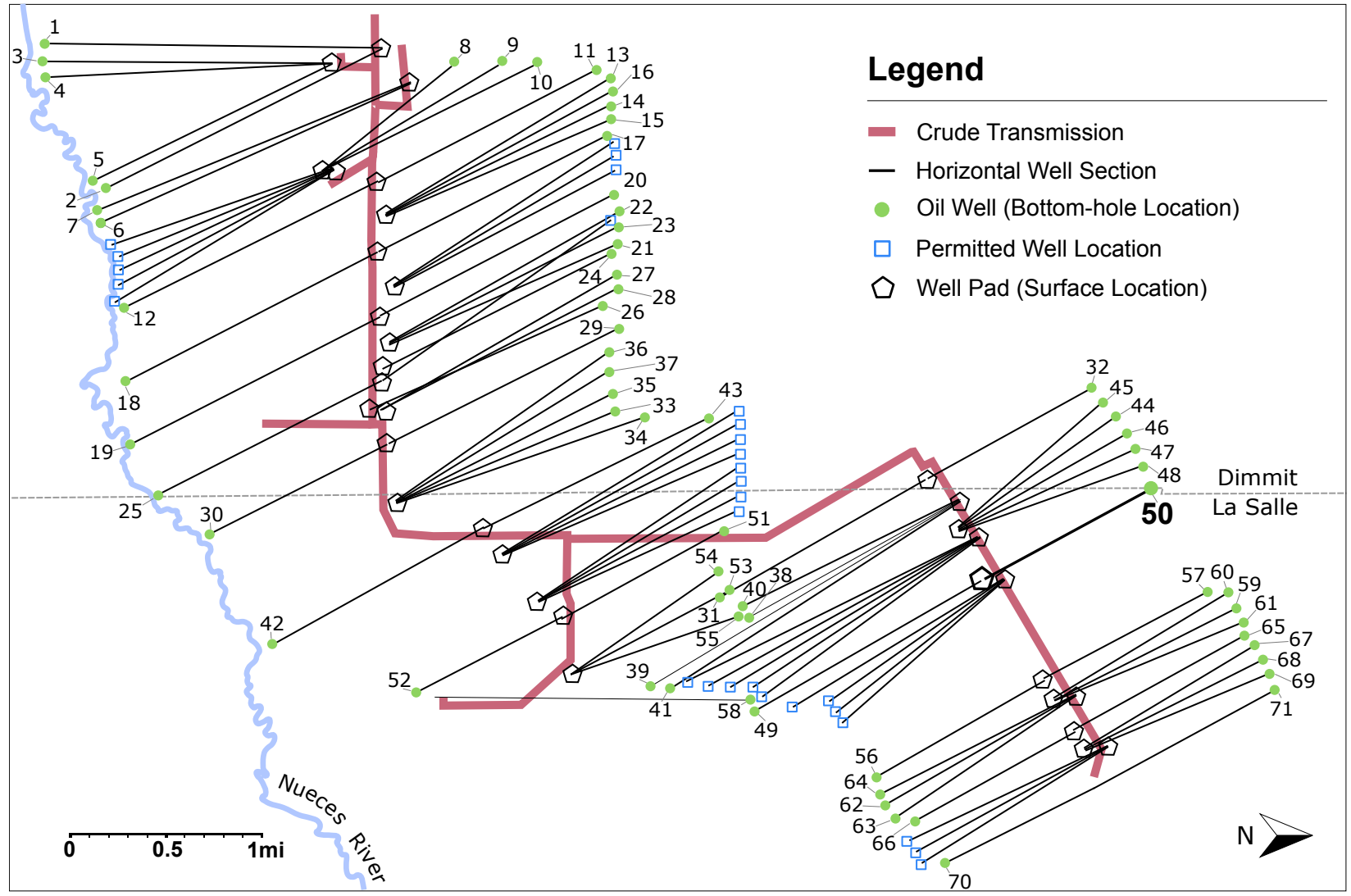

Figure B1: Map of a lease in the Eagle Ford with 71 wells connected to a single pipeline (after: RRC Texas, accessed on April 3, 2017). The production data for all wells are lumped together and assigned to well number 50.

span the bottom-hole area of 10,500 acres.

In the DrillingInfo software, this particular lease example is reported as one unallocated well with the API number 42283-32XXX-00 and the production data detailed in Table B1. The well count varies in each month and mostly increases until the maximum well count of 65 is reached. This well count, reported by DrillingInfo, is inaccurate because we counted 71 wells that belong to the same lease.

The cumulative mass produced by all wells, along with the corresponding number of the wells, are plotted vs. time on production in Fig. B2. During the first four months, there was only one well contributing to the production. Later on, 
more wells were drilled, resulting in the cumulative total oil mass curving up parabolically, until the maximum well count reached 65 wells. Naturally, as the reservoir pressure declines, the rate of oil production of each well must decrease with time, resulting in the cumulative oil production that curves down. Consequently, the cumulative oil mass curve shown in Fig. B2 cannot be matched with any physics-based model $^{3}$ and must be back-allocated to individual wells.

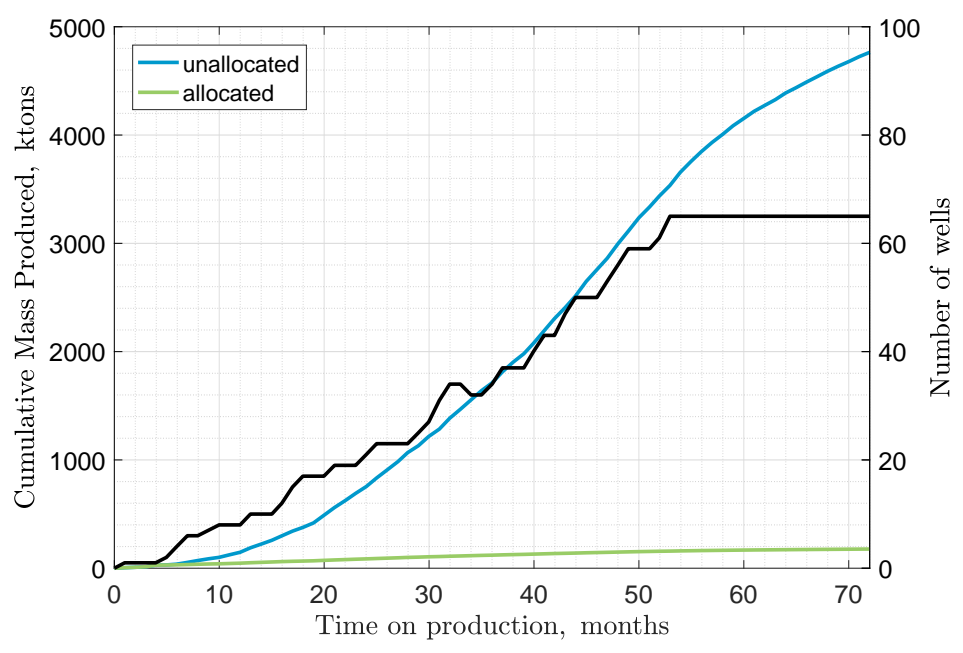

Figure B2: The cumulative mass produced from an Eagle Ford lease in Fig. B1. The blue and black lines are the unallocated production and number of wells that contribute each month. The allocated production of an equivalent average well is shown as the green line.

Well Allocation Method. Oil production from unallocated total production records must be allocated to individual wells so that we can use our predictive model for shale oil production. We consider the total mass produced as the sum of oil and gas masses:

$$
\text { mass produced }=\text { monthly Oil }(\mathrm{bbl}) \times 5.615 \frac{\mathrm{cuft}}{\mathrm{bbl}} \times(0.3048)^{3} \frac{\mathrm{m}^{3}}{\mathrm{cuft}} \times\left(\rho_{o}+\rho_{g} \times \mathrm{GOR} \times \frac{1}{5.615} \frac{\mathrm{bbl}}{\mathrm{cuft}}\right)
$$

where mass produced is in $\mathrm{kg}$, GOR is gas-oil ratio in $\mathrm{scf} / \mathrm{STB}$ and oil and gas density in $\mathrm{kg} / \mathrm{m}^{3}$ are:

$$
\rho_{o}=\frac{141.5}{131.5+\mathrm{API}} \times \rho_{\text {water }} \text { and } \rho_{g}=\mathrm{SG}_{\text {gas }} \times \rho_{\text {air }}
$$

Once we have the monthly mass production, the simplest way to perform the allocation is to divide the total mass produced in a given month by the well corresponding count:

$$
\text { allocated mass produced }=\frac{\text { unallocated mass produced }}{\text { number of wells }}
$$

The allocated cumulative mass produced in each month can then be written as follows:

$$
\bar{N}_{i}=\sum_{i=1}^{n}\left(\frac{m_{i}}{x_{i}}\right)
$$

Here $\bar{N}_{i}$ is the allocated cumulative mass produced at the month- $i, m_{i}$ is the unallocated monthly mass produced at month- $i$ (lease production), $x_{i}$ is the number of wells in month- $i$, and $i$ counts months on production $(i=1,2, \ldots, n)$. All steps in our well allocation procedure are detailed in Table B2. Before the allocation, cumulative production has the shape of a convex-down parabola that violates the natural depletion mechanisms for a physical well. Our allocation method results in a convex-up cumulative mass production curve that follows the reduction of reservoir pressure during production, see the green curve in Fig. B2.

\footnotetext{
${ }^{3}$ The hyperbolic decline model will yield rates that never go to zero and arbitrarily large cumulative production.
} 
Reconstruction of Lease Production. Once we have allocated lease production, we are able to predict the EUR for each well. However, in order to conserve mass, the predicted production for each allocated well must be mapped back to lease production. This back-mapping procedure is not difficult as long as we record the number of wells at each time step. Following Eq. (B2), we can quickly obtain the unallocated mass production of each month as follows:

$$
\text { lease production }=\text { allocated mass produced } \times \text { number of wells }
$$

In practice, we may only have the cumulative production curve for the average allocated well depicted in Fig. B2. We can calculate the unallocated lease production in each month by differencing cumulative production of the allocated well at each time step. The cumulative lease production can be written as:

$$
N_{i}=\sum_{i=1}^{n} x_{i}\left(\bar{N}_{i}-\bar{N}_{i-1}\right)
$$

Where $N_{i}$ is the cumulative lease mass produced at the month- $i, \bar{N}_{i}$ is the allocated cumulative mass produced in month- $i$ (we take $\bar{N}_{0}=0$ ktons), $x_{i}$ is the number of wells in month- $i$, and $(i=1,2, \ldots, n)$, where $n$ is the number of months on production in the lease record.

Table B1: Monthly production data of Lease 153XX or API 42-283-323XX-00

\begin{tabular}{ccccc}
\hline $\begin{array}{c}\text { Production } \\
\text { Date }\end{array}$ & $\begin{array}{c}\text { Oil } \\
(\mathrm{bbl})\end{array}$ & $\begin{array}{c}\text { Gas } \\
\text { (Mscf) }\end{array}$ & $\begin{array}{c}\text { Water } \\
(\mathrm{bbl})\end{array}$ & $\begin{array}{c}\text { Well } \\
\text { Count }\end{array}$ \\
$12 / 1 / 2010$ & 11,755 & 12,350 & 7,423 & 1 \\
$1 / 1 / 2011$ & 9,427 & 5,249 & 5,953 & 1 \\
$2 / 1 / 2011$ & 11,903 & 5,711 & 7,517 & 1 \\
$3 / 1 / 2011$ & 32,693 & 19,562 & 20,645 & 1 \\
$4 / 1 / 2011$ & 5,527 & 1,557 & 3,490 & 2 \\
$5 / 1 / 2011$ & 15,934 & 7,546 & 10,062 & 4 \\
$6 / 1 / 2011$ & 40,382 & 32,629 & 25,500 & 6 \\
$7 / 1 / 2011$ & 40,715 & 33,813 & 25,711 & 6 \\
$8 / 1 / 2011$ & 39,333 & 42,469 & 24,838 & 7 \\
$9 / 1 / 2011$ & 33,462 & 13,968 & 21,131 & 8 \\
$10 / 1 / 2011$ & 55,802 & 21,863 & 35,238 & 8 \\
$11 / 1 / 2011$ & 57,737 & 21,748 & 36,460 & 8 \\
$12 / 1 / 2011$ & 98,339 & 66,987 & 62,099 & 10 \\
$1 / 1 / 2012$ & 83,726 & 56,841 & 52,871 & 10 \\
$2 / 1 / 2012$ & 86,653 & 79,465 & 54,720 & 10 \\
$3 / 1 / 2012$ & 94,809 & 119,370 & 59,870 & 12 \\
$4 / 1 / 2012$ & 106,934 & 144,435 & 67,527 & 15 \\
$5 / 1 / 2012$ & 81,498 & 123,674 & 51,464 & 17 \\
$6 / 1 / 2012$ & 102,460 & 115,400 & 64,702 & 17 \\
$7 / 1 / 2012$ & 166,885 & 243,417 & 105,385 & 17 \\
$8 / 1 / 2012$ & 177,752 & 277,829 & 112,247 & 19 \\
$9 / 1 / 2012$ & 157,201 & 290,617 & 99,269 & 19 \\
$10 / 1 / 2012$ & 157,442 & 293,739 & 99,422 & 19 \\
$11 / 1 / 2012$ & 155,811 & 263,451 & 98,392 & 21 \\
& & & &
\end{tabular}




$\begin{array}{ccccc}12 / 1 / 2012 & 188,747 & 276,631 & 119,190 & 23 \\ 1 / 1 / 2013 & 185,089 & 286,820 & 115,903 & 23 \\ 2 / 1 / 2013 & 187,400 & 361,561 & 117,350 & 23 \\ 3 / 1 / 2013 & 183,155 & 428,418 & 114,692 & 23 \\ 4 / 1 / 2013 & 155,920 & 383,981 & 97,637 & 25 \\ 5 / 1 / 2013 & 203,920 & 430,697 & 127,695 & 27 \\ 6 / 1 / 2013 & 168,164 & 431,030 & 105,305 & 31 \\ 7 / 1 / 2013 & 237,870 & 528,778 & 148,955 & 34 \\ 8 / 1 / 2013 & 204,620 & 515,141 & 128,133 & 34 \\ 9 / 1 / 2013 & 213,397 & 579,924 & 133,629 & 32 \\ 10 / 1 / 2013 & 201,047 & 612,705 & 125,896 & 32 \\ 11 / 1 / 2013 & 178,213 & 592,611 & 111,597 & 34 \\ 12 / 1 / 2013 & 242,573 & 690,535 & 151,900 & 37 \\ 1 / 1 / 2014 & 219,223 & 655,856 & 122,326 & 37 \\ 2 / 1 / 2014 & 191,462 & 553,561 & 106,835 & 37 \\ 3 / 1 / 2014 & 213,225 & 604,804 & 118,979 & 40 \\ 4 / 1 / 2014 & 286,031 & 651,832 & 159,604 & 43 \\ 5 / 1 / 2014 & 267,200 & 690,462 & 149,097 & 43 \\ 6 / 1 / 2014 & 250,062 & 612,366 & 139,534 & 47 \\ 7 / 1 / 2014 & 255,191 & 578,674 & 142,396 & 50 \\ 8 / 1 / 2014 & 330,378 & 736,667 & 184,350 & 50 \\ 9 / 1 / 2014 & 267,676 & 788,338 & 149,362 & 50 \\ 10 / 1 / 2014 & 250,374 & 686,188 & 139,708 & 53 \\ 11 / 1 / 2014 & 327,482 & 733,613 & 182,734 & 56 \\ 12 / 1 / 2014 & 277,747 & 707,103 & 154,982 & 59 \\ 1 / 1 / 2015 & 306,664 & 697,782 & 217,629 & 59 \\ 2 / 1 / 2015 & 245,764 & 634,524 & 174,410 & 59 \\ 3 / 1 / 2015 & 221,023 & 564,284 & 156,852 & 61 \\ 4 / 1 / 2015 & 243,057 & 528,138 & 172,489 & 65 \\ 5 / 1 / 2015 & 288,341 & 534,509 & 204,625 & 65 \\ 6 / 1 / 2015 & 246,013 & 525,615 & 174,587 & 65 \\ 7 / 1 / 2015 & 215,486 & 266,194 & 152,923 & 65 \\ 8 / 1 / 2015 & 208,437 & 569,353 & 147,920 & 65 \\ 9 / 1 / 2015 & 185,976 & 515,584 & 131,981 & 65 \\ 10 / 1 / 2015 & 187,137 & 468,540 & 132,805 & 65 \\ 11 / 1 / 2015 & 165,843 & 450,327 & 117,693 & 65 \\ 12 / 1 / 2015 & 157,109 & 456,515 & 111,495 & 65 \\ 1 / 1 / 2016 & 134,315 & 391,612 & 34,622 & 65 \\ 2 / 1 / 2016 & 132,082 & 347,745 & 34,046 & 65 \\ 3 / 1 / 2016 & 138,433 & 354,005 & 35,683 & 65 \\ 6 / 1 / 2016 & 123,606 & 409,034 & 31,862 & 65\end{array}$




\begin{tabular}{ccccc}
$7 / 1 / 2016$ & 118,240 & 430,513 & 30,478 & 65 \\
$8 / 1 / 2016$ & 114,365 & 444,446 & 29,479 & 65 \\
$9 / 1 / 2016$ & 106,273 & 421,164 & 27,394 & 65 \\
$10 / 1 / 2016$ & 107,956 & 416,936 & 27,827 & 65 \\
$11 / 1 / 2016$ & 99,859 & 386,615 & 25,740 & 65 \\
\hline
\end{tabular}

Table B2: Allocating steps summarized in a table

\begin{tabular}{|c|c|c|c|c|c|}
\hline $\begin{array}{c}\text { Time } \\
\text { (Months) }\end{array}$ & $\begin{array}{l}\text { Mass Produced } \\
\text { (ktons) }\end{array}$ & $\begin{array}{c}\text { Unallocated } \\
\text { Cumulative Mass }\end{array}$ & $\begin{array}{l}\text { Well } \\
\text { Count }\end{array}$ & $\begin{array}{c}\text { Mass/Went } \\
\text { ktons }\end{array}$ & $\begin{array}{c}\text { Allocated } \\
\text { Cumulative Mass }\end{array}$ \\
\hline 1.00 & 4.94 & 4.94 & 1 & 4.94 & 4.94 \\
\hline 2.03 & 3.83 & 8.77 & 1 & 3.83 & 8.77 \\
\hline 3.07 & 4.84 & 13.61 & 1 & 4.84 & 13.61 \\
\hline 4.00 & 14.72 & 28.33 & 1 & 14.72 & 28.33 \\
\hline 5.03 & 2.25 & 30.57 & 2 & 1.13 & 29.46 \\
\hline 6.03 & 6.69 & 37.27 & 4 & 1.67 & 31.13 \\
\hline 7.07 & 16.42 & 53.68 & 6 & 2.74 & 33.86 \\
\hline 8.07 & 17.10 & 70.79 & 6 & 2.85 & 36.71 \\
\hline 9.10 & 15.99 & 86.78 & 7 & 2.28 & 39.00 \\
\hline 10.13 & 13.60 & 100.38 & 8 & 1.70 & 40.70 \\
\hline 11.13 & 23.44 & 123.83 & 8 & 2.93 & 43.63 \\
\hline 12.17 & 23.47 & 147.30 & 8 & 2.93 & 46.56 \\
\hline 13.17 & 41.31 & 188.61 & 10 & 4.13 & 50.69 \\
\hline 14.20 & 34.04 & 222.65 & 10 & 3.40 & 54.10 \\
\hline 15.23 & 35.23 & 257.88 & 10 & 3.52 & 57.62 \\
\hline 16.20 & 41.20 & 299.08 & 12 & 3.43 & 61.05 \\
\hline 17.23 & 43.47 & 342.56 & 15 & 2.90 & 63.95 \\
\hline 18.23 & 34.24 & 376.80 & 17 & 2.01 & 65.97 \\
\hline 19.27 & 41.66 & 418.45 & 17 & 2.45 & 68.42 \\
\hline 20.27 & 70.11 & 488.56 & 17 & 4.12 & 72.54 \\
\hline 21.30 & 72.27 & 560.83 & 19 & 3.80 & 76.34 \\
\hline 22.33 & 63.91 & 624.74 & 19 & 3.36 & 79.71 \\
\hline 23.33 & 66.14 & 690.88 & 19 & 3.48 & 83.19 \\
\hline 24.37 & 63.35 & 754.23 & 21 & 3.02 & 86.21 \\
\hline 25.37 & 79.29 & 833.52 & 23 & 3.45 & 89.65 \\
\hline 26.40 & 75.25 & 908.77 & 23 & 3.27 & 92.92 \\
\hline 27.43 & 76.19 & 984.96 & 23 & 3.31 & 96.24 \\
\hline 28.37 & 82.44 & 1067.40 & 23 & 3.58 & 99.82 \\
\hline 29.40 & 63.39 & 1130.79 & 25 & 2.54 & 102.36 \\
\hline 30.40 & 85.67 & 1216.46 & 27 & 3.17 & 105.53 \\
\hline 31.43 & 68.37 & 1284.82 & 31 & 2.21 & 107.74 \\
\hline 32.43 & 99.93 & 1384.76 & 34 & 2.94 & 110.67 \\
\hline 33.47 & 83.19 & 1467.94 & 34 & 2.45 & 113.12 \\
\hline
\end{tabular}




\begin{tabular}{|c|c|c|c|c|c|}
\hline 34.50 & 86.76 & 1554.70 & 32 & 2.71 & 115.83 \\
\hline 35.50 & 84.46 & 1639.16 & 32 & 2.64 & 118.47 \\
\hline 36.53 & 72.45 & 1711.62 & 34 & 2.13 & 120.60 \\
\hline 37.53 & 101.91 & 1813.52 & 37 & 2.75 & 123.36 \\
\hline 38.57 & 89.13 & 1902.65 & 37 & 2.41 & 125.77 \\
\hline 39.60 & 77.84 & 1980.49 & 37 & 2.10 & 127.87 \\
\hline 40.53 & 95.98 & 2076.46 & 40 & 2.40 & 130.27 \\
\hline 41.57 & 116.29 & 2192.75 & 43 & 2.70 & 132.97 \\
\hline 42.57 & 112.25 & 2305.00 & 43 & 2.61 & 135.58 \\
\hline 43.60 & 101.66 & 2406.67 & 47 & 2.16 & 137.75 \\
\hline 44.60 & 107.21 & 2513.88 & 50 & 2.14 & 139.89 \\
\hline 45.63 & 134.32 & 2648.19 & 50 & 2.69 & 142.58 \\
\hline 46.67 & 108.82 & 2757.02 & 50 & 2.18 & 144.75 \\
\hline 47.67 & 105.18 & 2862.20 & 53 & 1.98 & 146.74 \\
\hline 48.70 & 133.14 & 2995.34 & 56 & 2.38 & 149.12 \\
\hline 49.70 & 116.68 & 3112.02 & 59 & 1.98 & 151.09 \\
\hline 50.73 & 124.68 & 3236.70 & 59 & 2.11 & 153.21 \\
\hline 51.77 & 99.92 & 3336.62 & 59 & 1.69 & 154.90 \\
\hline 52.70 & 99.49 & 3436.10 & 61 & 1.63 & 156.53 \\
\hline 53.73 & 98.82 & 3534.92 & 65 & 1.52 & 158.05 \\
\hline 54.73 & 121.13 & 3656.05 & 65 & 1.86 & 159.92 \\
\hline 55.77 & 100.02 & 3756.07 & 65 & 1.54 & 161.45 \\
\hline 56.77 & 90.53 & 3846.60 & 65 & 1.39 & 162.85 \\
\hline 57.80 & 84.74 & 3931.34 & 65 & 1.30 & 164.15 \\
\hline 58.83 & 75.61 & 4006.95 & 65 & 1.16 & 165.31 \\
\hline 59.83 & 78.62 & 4085.56 & 65 & 1.21 & 166.52 \\
\hline 60.87 & 67.42 & 4152.99 & 65 & 1.04 & 167.56 \\
\hline 61.87 & 66.00 & 4218.99 & 65 & 1.02 & 168.58 \\
\hline 62.90 & 54.61 & 4273.60 & 65 & 0.84 & 169.42 \\
\hline 63.93 & 53.70 & 4327.30 & 65 & 0.83 & 170.24 \\
\hline 64.90 & 60.16 & 4387.46 & 65 & 0.93 & 171.17 \\
\hline 65.93 & 50.08 & 4437.54 & 65 & 0.77 & 171.94 \\
\hline 66.93 & 51.44 & 4488.98 & 65 & 0.79 & 172.73 \\
\hline 67.97 & 50.25 & 4539.23 & 65 & 0.77 & 173.50 \\
\hline 68.97 & 49.67 & 4588.91 & 65 & 0.76 & 174.27 \\
\hline 70.00 & 46.50 & 4635.40 & 65 & 0.72 & 174.98 \\
\hline 71.03 & 43.21 & 4678.61 & 65 & 0.66 & 175.65 \\
\hline 72.03 & 45.35 & 4723.96 & 65 & 0.70 & 176.35 \\
\hline 73.07 & 40.60 & 4764.56 & 65 & 0.62 & 176.97 \\
\hline
\end{tabular}

